Review

\title{
A metabolic perspective of late onset Alzheimer's disease
}

\author{
Miren Ettcheto ${ }^{\mathrm{a}, \mathrm{b}, \mathrm{c}, \mathrm{d}, 1}$, Amanda Cano ${ }^{\mathrm{d}, \mathrm{e}, \mathrm{f}, 1}$, Oriol Busquets ${ }^{\mathrm{a}, \mathrm{b}, \mathrm{c}, \mathrm{d}}$, Patricia Regina Manzine ${ }^{\mathrm{a}, \mathrm{c}, \mathrm{d}, \mathrm{g}}$, \\ Elena Sánchez-López ${ }^{\mathrm{d}, \mathrm{e}, \mathrm{f}}$, Rubén D. Castro-Torres ${ }^{\mathrm{a}, \mathrm{c}, \mathrm{d}, \mathrm{h}, \mathrm{i}}$, Carlos Beas-Zarate ${ }^{\mathrm{i}}$, Ester Verdaguer, ${ }^{\mathrm{c}, \mathrm{d}, \mathrm{h}}$, \\ María Luisa García ${ }^{\mathrm{d}, \mathrm{e}, \mathrm{f}}$, Jordi Olloquequi ${ }^{\mathrm{j}}$, Carme Auladell ${ }^{\mathrm{c}, \mathrm{d}, \mathrm{h}}$, Jaume Folch $^{\mathrm{b}, \mathrm{d}}$, \\ Antoni Camins ${ }^{\mathrm{a}, \mathrm{c}, \mathrm{d}, *}$
}

\footnotetext{
${ }^{a}$ Departament de Farmacologia, Toxicologia i Química Terapèutica, Facultat de Farmàcia i Ciències de l'Alimentació, Universitat de Barcelona, Barcelona, Spain

${ }^{\mathrm{b}}$ Departament de Bioquímica i Biotecnologia, Facultat de Medicina i Ciències de la Salut, Universitat Rovira i Virgili, Reus, Spain

${ }^{\mathrm{c}}$ Institut de Neurociències, Universitat de Barcelona, Barcelona, Spain

${ }^{\mathrm{d}}$ Biomedical Research Networking Centre in Neurodegenerative Diseases (CIBERNED), Madrid, Spain

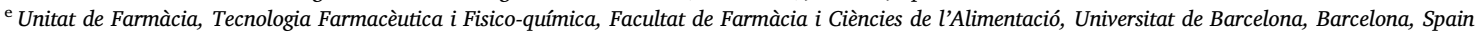

${ }_{\mathrm{f}}^{\mathrm{f}}$ Institute of Nanoscience and Nanotechnology (IN2UB), Universitat de Barcelona, Spain

${ }^{g}$ Department of Gerontology, Federal University of São Carlos (UFSCar), São Carlos, SP, Brazil

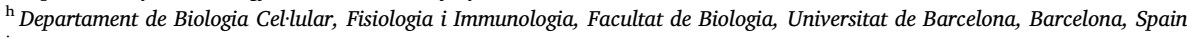

${ }^{\mathrm{i}}$ Laboratorio de Regeneración y Desarrollo Neural, Instituto de Neurobiología, Departamento de Biología Celular y Molecular, CUCBA, Mexico

${ }^{\mathrm{j}}$ Instituto de Ciencias Biomédicas, Facultad de Ciencias de la Salud, Universidad Autónoma de Chile, Talca, Chile
}

\section{A R T I C L E I N F O}

\section{Keywords:}

Alzheimer's disease

Type 2 diabetes mellitus

Insulin

c-Jun N-terminal kinase inhibitors

Licochalcone A

Neuroinflammation

Reticulum stress

\begin{abstract}
A B S T R A C T
After decades of research, the molecular neuropathology of Alzheimer's disease (AD) is still one of the hot topics in biomedical sciences. Some studies suggest that soluble amyloid $\beta(A \beta)$ oligomers act as causative agents in the development of $\mathrm{AD}$ and could be initiators of its complex neurodegenerative cascade. On the other hand, there is also evidence pointing to $A \beta$ oligomers as mere aggravators, with an arguable role in the origin of the disease.

In this line of research, the relative contribution of soluble $A \beta$ oligomers to neuronal damage associated with metabolic disorders such as Type 2 Diabetes Mellitus (T2DM) and obesity is being actively investigated. Some authors have proposed the endoplasmic reticulum (ER) stress and the induction of the unfolded protein response (UPR) as important mechanisms leading to an increase in $\mathrm{A} \beta$ production and the activation of neuroinflammatory processes. Following this line of thought, these mechanisms could also cause cognitive impairment.

The present review summarizes the current understanding on the neuropathological role of $A \beta$ associated with metabolic alterations induced by an obesogenic high fat diet (HFD) intake. It is believed that the combination of these two elements has a synergic effect, leading to the impairement of ER and mitochondrial functions, glial reactivity status alteration and inhibition of insulin receptor (IR) signalling. All these metabolic alterations would favour neuronal malfunction and, eventually, neuronal death by apoptosis, hence causing cognitive impairment and laying the foundations for late-onset $\mathrm{AD}$ (LOAD).
\end{abstract}

Moreover, since drugs enhancing the activation of cerebral insulin pathway can constitute a suitable strategy

Abbreviations: A $\beta$, amyloid $\beta$; AD, Alzheimer's disease; AChEI, anticholinesterase inhibitors; AMPAR, $\alpha$-amino-3-hydroxy-5-methyl-4-isoxazolepropionic acid re-

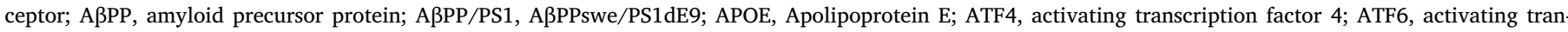

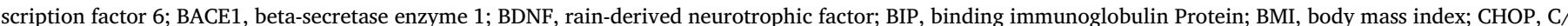

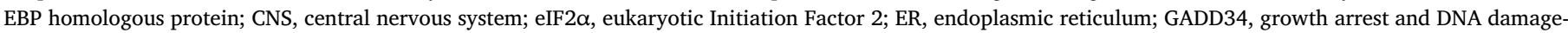

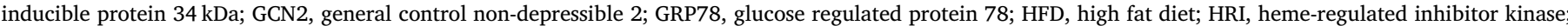

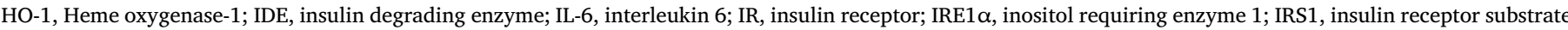

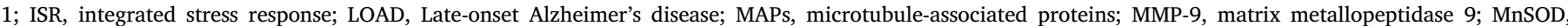

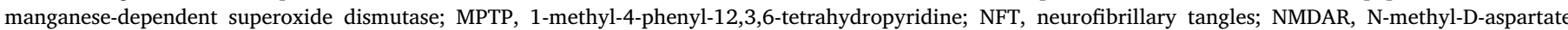

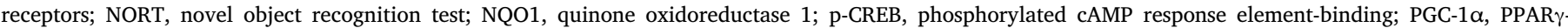

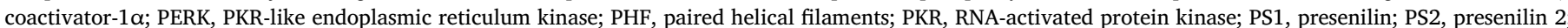

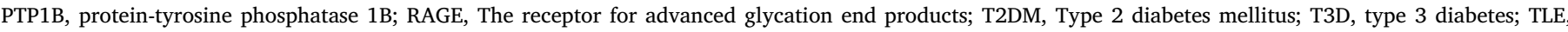
temporal lobe epilepsy; TRAF2, tumour necrosis factor receptor associated factor-2; TNF $\alpha$, tumour necrosis factor $\alpha$; UPR, unfolded protein response

* Corresponding author at: Unitat de Farmacologia i Farmacognòsia, Facultat de Farmàcia i Ciències de l'Alimentació, Universitat deBarcelona, Barcelona, Spain. Av. Joan XXIII 27/31, E-08028 Barcelona, Spain.

E-mail address: camins@ub.edu (A. Camins).

${ }^{1}$ Both authors have contributed equally. 
for the prevention of $\mathrm{AD}$, we also discuss the scope of therapeutic approaches such as intranasal administration of insulin in clinical trials with $\mathrm{AD}$ patients.

\section{Introduction}

The study of Alzheimer's disease (AD) began in the early twentieth century, when the German physician Alois Alzheimer described the first case of this pathology in a 51-year old woman called Auguste Deter [1]. Her symptoms included remarkable memory loss, language difficulties and personality changes. After the post-mortem examination, the brain autopsy revealed specific neuropathological changes in the cerebral cortex [1-4], now known as the classical morphological symptoms of AD: amyloid $\beta$ (A $\beta)$ peptide plaques derived of the activity of the amyloidogenic pathway and neurofibrillary tangles (NFTs), composed by hyperphosphorylated tau protein [3-8].

At present, the aetiological hypothesis most supported by the scientific community is the "amyloid cascade hypothesis", which is summarized in Fig. 1. According to this hypothesis, under physiological conditions amyloid $\beta$ protein percussor (A $\beta P P$ ) is cleaved by the enzyme $\alpha$-secretase, following the non-amyloidogenic pathway. This precludes formation of amyloidogenic peptides and leads to a release of secreted A $\beta P P$ alpha (sA $\beta P P \alpha$ ), which has neuroprotective properties [5]. On the contrary, in the amyloidogenic pathway, AßPP is cleaved by $\beta$-secretase (BACE-1) at $N$-terminus and, in turn, $\gamma / \varepsilon$-secretase cleaves it at the C-terminus to yield secreted A $\beta P P$ (sA $\beta P P$ ), A $\beta 40 / 42$ fragments (which remain in the extracellular space) and a C-terminal fragment with 99 amino acids (C99) that can be translocated to the nucleus. Here, it may induce expression of genes that promote neuronal death by apoptosis. Moreover, the soluble $A \beta$ oligomers generated in this way affect synapse function, decrease neuronal plasticity, alter energy and glucose metabolism, induce oxidative stress and mitochondrial dysfunction, and disturb celular calcium homeostasis [2,5].

During the early 1990s, some genetic factors -apart from AßPPwere shown to increase the risk of developing the disease, such as apolipoprotein E (APOE) or presenilin 1 and 2 (PS1 and PS2) [7-11].
These factors were also involved in the amyloid cascade. For instance, the allele for APOE $\varepsilon 4$ was been shown to impair $A \beta$ clearance and promote its aggregation, leading to increased severity of this amyloid pathology [7-12]. In spite of this, the existence of other factors that can contribute to the pathogenesis of $\mathrm{AD}$ emphasizes its complexity. Some of these risk factors are shown in Fig. 2.

Against this background, $\mathrm{AD}$ patients were classified into two groups. The first one was formed for those subjects that developed the pathology due to genetic causes leading to the production of classical biomarkers like $\mathrm{A} \beta$. This group covered about 3\% of $\mathrm{AD}$ patients and was dubbed "familial or early-onset AD". The remaining $97 \%$ of patients were categorized as "sporadic or late-onset AD" (LOAD), whose progression was associated with advanced age, hypertension, hyperlipidaemia, coronary disease, obesity and type 2 diabetes mellitus (T2DM) [12-14].

T2DM is a complex disease with a chronic evolution that requires continuous medical care, mainly focused on the reduction of global cardiovascular risk, peripheral complications and cognitive loss [15]. Unlike type 1 diabetes mellitus (T1DM), an autoimmune disorder characterized by the selective destruction of insulin-producing $\beta$-cells $[16,17]$, in T2DM there is an alteration in the mechanisms of uptake and/or secretion of insulin. This leads to a chronic increase in blood levels of glucose, resulting in a higher risk of macro and microvascular complications. T2DM is also associated with insulin resistance (IR), which is characterized by lower insulin activity at the cellular level, and affects the metabolism of carbohydrates, lipids and proteins [15]. As we have mentioned, in addition to a risk factor for cardiovascular pathologies, T2DM is also an independent risk factor for LOAD [11-14]. Specifically, it is widely recognized that T2DM and AD share several kinds of abnormalities, including increased oxidative stress, impaired glucose metabolism and insulin resistance characterized by continuous hyperinsulinemia $[12,12,13,14,18]$. Likewise, some studies have

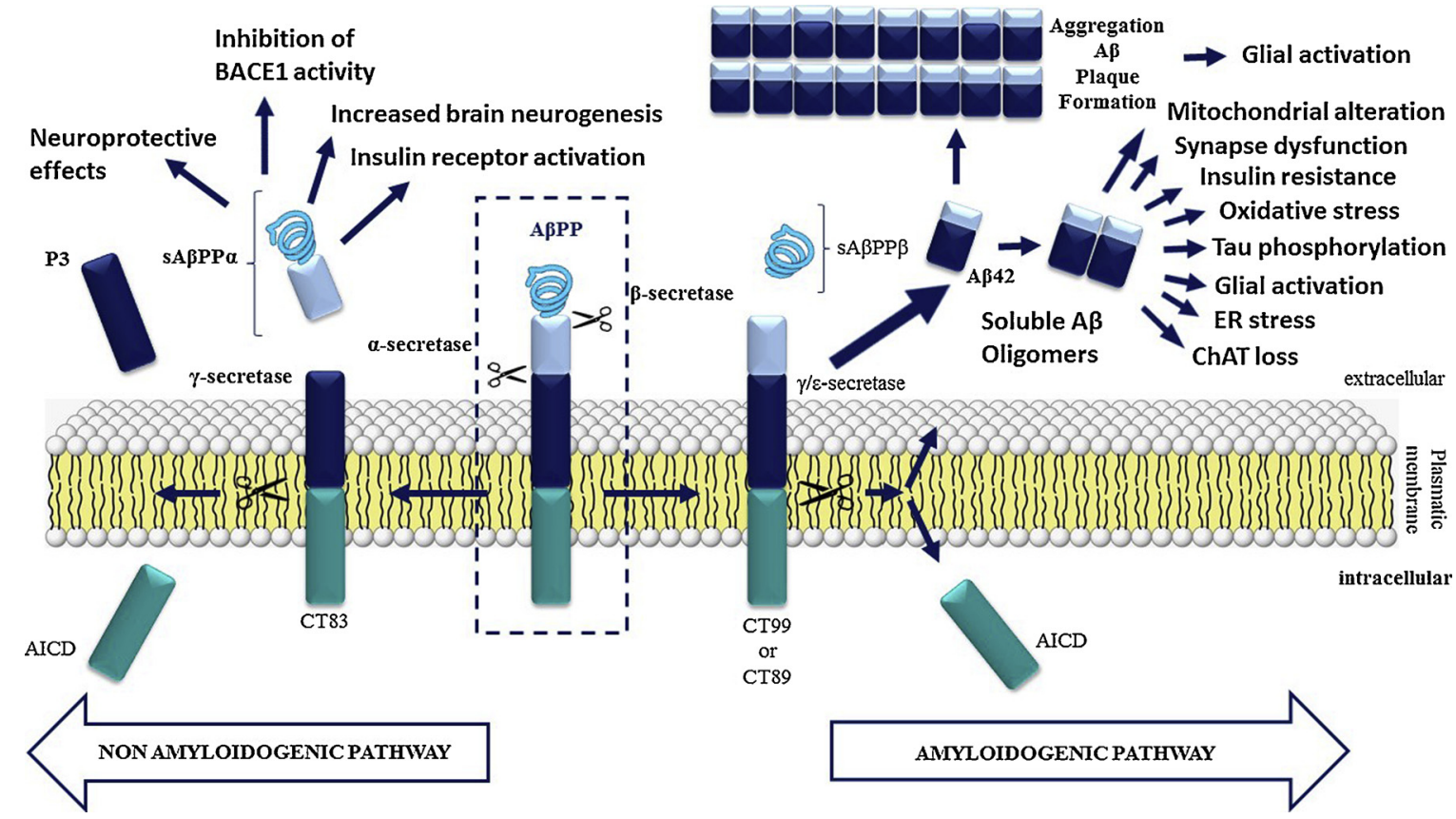

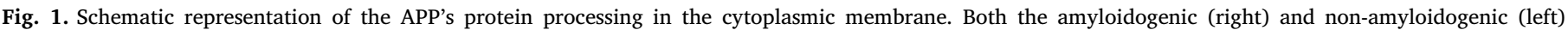

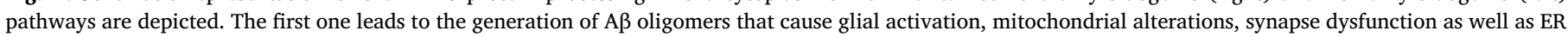

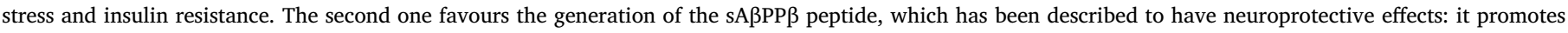
neurogenesis, favours insulin receptor activation and inhibits BACE1. 


\section{RISK FACTORS IN ALZHEIMER'S DISEASE}

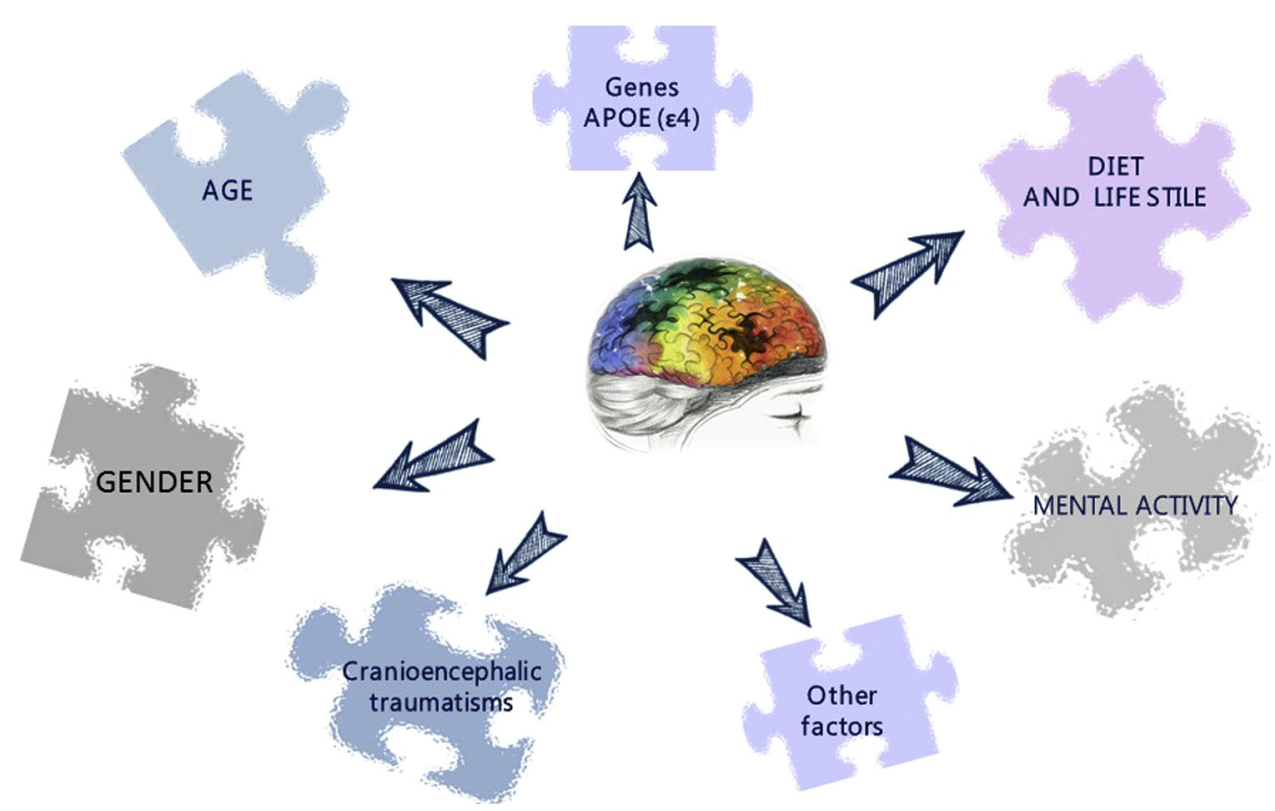

Fig. 2. Some risk factors for the development of sporadic AD. Age, APOE $\varepsilon 4$ mutation, diet and lifestyle, gender, mental activity, cranioencephalic traumatisms and others factors such as lack of social engagement have been associated to the onset and/or progression of $\mathrm{AD}$.

focused on the role of insulin receptor (IR), which might be an important player in the pathology of $\mathrm{AD}$, by contributing to the biochemical, molecular and histopathological characteristics of the pathology [13,19-27].

Given that the origin of the pathology is still unknown, and that there seem to be many players involved in its development, $\mathrm{AD}$ has been defined as a multifactorial disease (Fig. 2). Consequently, there are different research areas, in addition to neuroscience, trying to elucidate the origin of this pathology. In fact, prospective epidemiological studies have identified metabolic syndrome and T2MD as risk factors for multiple diseases of the nervous system [18-20]. Furthermore, animal studies have shown that hypercaloric diets affect the structure and functions of the hippocampus, although the specific mechanisms are unclear $[28,29]$. Thus, it has been reported that AßPPswe/PS1dE9 (A $\beta P P / P S 1)$ transgenic mice fed with a diet enriched in palmitic acid, showed reduced IR and increased insoluble $A \beta$ peptide levels, as well as cognitive deficits [30]. Moreover, Ho and colleagues found evidence linking insulin resistance and increased relative risk for $\mathrm{AD}$ neuropathology development, by demonstrating that IR signalling can influence $A \beta$ production in the brain [31]. These results evidenced the relationship between metabolic alterations and progression of $\mathrm{AD}$ features, thus reinforcing the hypothesis of a metabolic aetiology of AD. Indeed, it has been proposed to re-name $\mathrm{AD}$ as "type 3 diabetes mellitus" (T3DM) or brain-specific diabetes [32].

The present review is a state-of-the-art about the relation among obesity, A $\beta$ oligomers and the IR modulation. In addition, we discuss the potential application of drugs modulating the brain insulin receptor pathway as targets for $\mathrm{AD}$ prevention.

\section{An historical overview of AD's hypotheses and available pharmacological treatments}

Altghough over a century has passed since AD was first described, the pathogenesis of this complex disease is still unclear. A number of theories about $\mathrm{AD}$ origin have been postulated so far and several drugs have been tested in accordance. The first one, proposed in the $80 \mathrm{~s}$, was the "cholinergic hypothesis", which suggested that a dysfunction of acetylcholine-containing neurons in the brain contributes substantially to the cognitive decline observed in $\mathrm{AD}$ patients [33-35]. This paradigm led to the development of the anticholinesterase inhibitors (AChEI), which are currently in the market and provide a symptomatic treatment of the disease [34-38]. However, these drugs only achieve a temporary improvement and they do not slow down or cure AD.

In 1992, a series of discoveries opened the door to the birth of the "amyloid cascade hypothesis", which we have already discussed. This hypothesis stressed the role of $\mathrm{A} \beta$ peptide deposition in $\mathrm{AD}$ pathogenesis, leading to neurofibrillary tangles, cell loss, vascular damage, and dementia [39-42]. Ostensibly, the appearance of plaques and the onset of $\mathrm{AD}$ would be related to the most common isoforms of $\mathrm{A} \beta,(1-40)$ and (1-42) [40-43]. However, some current preclinical discoveries pointed to $A \beta$ as a cofactor or aggravator involved in a complex network of pathological changes in the brain, instead of considering $A \beta$ as the main neurotoxin causing $\mathrm{AD}$ per se [44-48]. In any case, most drugs designed to inhibit amyloid synthesis have failed to modify the evolution of the disease. Notwithstanding, Verubescetat, a drug targeting $A \beta$ or inhibiting the $\beta$-site amyloid precursor protein cleaving enzyme 1 (BACE1), was reported to be more effective than placebo in treating $\mathrm{AD}$ $[47,48]$.

Besides A $\beta$ plaques, NFTs constitute the other main intracellular hallmark of AD. It was demonstrated that NFTs were composed of tau $[48,49]$, a microtubule-associated protein (MAP) which acts as a major regulator of microtubule formation [50-53]. Interestingly, it was observed that the hyperphosphorylation of tau led to unconstructed microtubules and the appearance of helically crossed filaments that aggregate to form the NFTs [50-53]. In some cases, the presence of NFTs was correlated with the degree of dementia in patients with $\mathrm{AD}$ [53]. All these observations paved the way for the "tau hypothesis", which postulates that the origin of $\mathrm{AD}$ is associated with an early conformational change in the structure of tau [54]. Indeed, it has been demonstrated that the reduction of hyperphosphorylated tau alleviates the cognitive alterations induced by $\mathrm{A} \beta$ in a transgenic mice model of $\mathrm{AD}$ [55]. Although in terms of research the tau hypothesis has been a "supporting actor" when compared to the amyloid hypothesis, some anti-tau therapies have shown promising results $[48,51]$. For instance, TRx0237 (LMTX) is being currently tested in a phase III clinical trial as an inhibitor of tau aggregation, capable of reducing tau-mediated 
neuronal damage (clinical trial NT02245568). By this mechanism, this drug could modify the course of $\mathrm{AD}$ [48]. On another front, it has been reported that soluble oligomers of $A \beta$ are able to accelerate the hyperphosphorylation of tau [4,50]. Nevertheless, although the two markers are closely related neuropathologically, a mechanism linking both theories is still missing.

Evidence showing inflammatory microglia consistently associated with senile plaques in $\mathrm{AD}$ led to the "inflammation hypothesis" [56]. Indeed, it is known that local reactivity responses, such as microgliosis and astrogliosis, could be involved in the development of AD by fostering a severe neuroinflammation through the release of cytokines [42,56-62]. However, while it is accepted that neuroinflammation contributes actively to the development of $\mathrm{AD}$, the fundamental question remains: is it the cause or the consequence of the underlying pathology? [60-64]. In this sense, the drug TTP488 (azeliragon), a receptor for advanced glycation end products (RAGE) antagonist with anti-amyloid and anti-inflammatory properties is in a phase III trail. It has been shown that this compound reduces amyloid uptake in brain and lowers the inflammatory reaction in glial cells (NCT02080364) [48].

Finally, another major hypothesis about AD is the "excitotoxic hypothesis", which describes how over-activation of glutamatergic transmission, especially of N-Methyl-D-aspartate receptors (NMDARs), leads to a massive influx of calcium $\left(\mathrm{Ca}^{2+}\right)$ that damages neurons [65]. In mammals, NMDARs are distributed throughout the brain and mainly in the hippocampus. The hyperactivation of these receptors leads to the activation of a wide variety of intracellular pathways, inducing homeostatic alterations and diminishing neuronal viability, eventually leading to neuronal death [66-68]. However, the mechanism by which this process is carried out remains unclear since, even though this hypothesis advocates for an over-activation of NMDARs, it has been observed that patients who developed $\mathrm{AD}$ actually had a reduction of the number of these receptors in the cellular membrane [68]. Apparently, the lack of receptors leads to an increase in their sensitivity, causing a continuous activation leading to a progressive neurodegeneration due to the excitotoxic damage [68-70]. Interestingly, this also seems to be related to $A \beta$, since it has been demonstrated that $A \beta$ causes an increase of the endocytosis of the NMDARs in cortical neurons, hence decreasing their expression in the membrane, which leads to an inhibition of synaptic plasticity [70]. Regarding the excitotoxic hypothesis, memantine, a NMDAR antagonist, was approved for the treatment of moderately severe to severe $\mathrm{AD}$ in 2002 by the European Agency for the Evaluation of Medical Products (EMEA). Unfortunately, as with any other approved treatment for $\mathrm{AD}$ so far, mematine only have shown symptomatic effects.

\section{Mechanisms linking obesity and cognitive decline: results from preclinical models}

Nearly 20 years ago, the Rotterdam study reported that T2DM patients had increased risk to suffer dementia [71,72]. Today, obesity and diabetes, two T2DM-related disorders, are well established risk factors for $\mathrm{AD}[11,23,71-74]$. In fact, it is of general concern that accumulation of fat in the adipose tissue favours the emergence of metabolic syndrome and T2DM, due to IR signalling deficits in peripheral tissues. What is, perhaps, not so widely known is that obesity also affects the central nervous system (CNS) and it is associated with an exacerbation of cognitive decline [75]. In this respect, data from the clinical study Whitehall II and other research projects established a relation between body mass index (BMI) values ( $>30 \mathrm{~kg} / \mathrm{m} 2$ ), aging ( $>50$ years old) and the onset of cognitive deficits [73-78]. Nowadays, the molecular mechanisms at fault are still being studied. For instance, many authors suggest that vascular risk factors and inflammatory responses could also have significant roles [79-82].

Since the pathogenesis of AD remains unclear, it is necessary to use mixed models covering different hypothesis of the disease, evaluating neuronal dysfunction, synapse loss and cell death, as well as potentiating $A \beta$ effects in order to better understand its role in these neuropathological events [80-86]. For now, it seems that A $\beta$ (1-42) oligomers would have a synergistic effect, accelerating the mechanisms related to cognitive impairment [86-89].

From a preclinical level, diet-induced obesity in in vivo models represents a suitable and reproducible method for identifying and understanding potential mechanisms involved in T2DM or IR-induced cognitive loss. Using this experimental approach, the research group of Marta Di Carlo reported that rodents under a high fat diet (HFD) $(60 \%$ kcal from fat) during 7 months exhibited brain abnormalities similar to the hallmarks of $\mathrm{AD}$, such as the increase in tau phosphorylation, neuroinflammation and memory loss [90]. In addition, they demonstrated that those mice showed an increase in $A \beta$ levels, which was associated with an increase in AßPP and BACE1 expression, both accompanied by an increase in oxidative stress and mitochondrial dysfunction. Our research group also demonstrated that mice fed with a HFD (45\% kcal from fat) for 12 months, displayed insoluble A $\beta$ peptide depositions in the brain, thus confirming the relation between the triad obesity, $A \beta$ and cognitive loss [91].

Moreover, other studies showed that HFD-induced brain insulin resistance could decrease synaptic vesicle recycling, thus diminishing synaptic strength and leading to deleterious effects on cognitive behaviour [92]. In a preclinical study, Hao and co-workers demonstrated that only three months of HFD feeding lead to a reversible deterioration of hippocampal synaptic plasticity, dendritic spine density and spatial memory in mice [93]. The authors propose that HFD activated a reversible microglial synaptic phagocytosis process. In this line of research, Osborne and co-workers provided key findings on the implication of $A \beta$ in memory loss in HFD fed rodents [94]. In this study, they showed that intrahippocampal infusion of A $333-42$ antibodies, with preferential affinity for aggregated $A \beta$ oligomers, improved the memory process in rodents with HFD-induced cognitive loss. In addition, the authors identified a potential mechanism involved in the process of cognitive impairment through the alteration of glutamate transmission by dysregulation of hippocampal $\alpha$-amino-3-hydroxy-5methyl-4-isoxazolepropionic acid receptors (AMPAR). However, other authors reported a detrimental cognitive effect of obesogenic HFD in 3xTgAD mice that was not associated with an increase in the brain levels of plaques, $A \beta$ and tau [95]. Contrarily, Vandal and co-workers reported that an obesogenic diet induced insulin resistance in both nontransgenic and 3xTgAD mice, which worsened due to the HFD-amyloid pathology exacerbation [96]. This suggests that HFD exerts a synergistic effect with $\mathrm{AD}$-like pathology in $3 \mathrm{xTgAD}$ mice. Moreover, it has been described that the noxious effects of $A \beta$ in brain can also contribute to pancreatic cell degeneration and insulin secretion, and, conversely, abnormal systemic changes might not only develop secondary to brain dysfunction but might also affect AD progression [97]. This suggests that the interactions between the brain and the periphery act as a vicious circle with a crucial role in the development and progression of AD [97]. These data are in line with other studies showing that brain $A \beta$ could bind to IR in the liver and favour peripheral insulin resistance $[98,99]$.

In another study, Ho and colleagues reported that HFD-induced insulin resistance was associated with a decrease in neuronal IR signalling and insulin degrading enzyme (IDE) expression in Tg2576 mice, thus promoting cognitive loss and increased $\mathrm{A} \beta$ plaque formation [31]. These results were confirmed by other researchers [100]. In this regard, it is important to emphasize that IDE does not only degrade insulin, but also A $\beta$ [30]. Thus, a decrease in its brain levels may contribute to both insulin signalling dysfunction and accumulation of $A \beta$. Likewise, other studies using animal models of obesity revealed that HFD induced an alteration in brain GLUT1 and GLUT3/GLUT4 glucose transporters, decreasing its up-take into the CNS. This was linked to cognitive deficits in the CA1 region of the hippocampus, which indicates an impaired synaptic plasticity [101]. Moreover, Ruiz and co-workers added 
another interesting point by reporting that HFD increased peripheral glucose levels in AßPP/PS1 mice, probably due to hypothalamic alterations [102]. Other studies provided data about the molecular mechanisms involved in obesity-mediated neurodegeneration. For instance, previous results from our group reported an important downregulation of PPAR $\gamma$-coactivator-1 $\alpha$ (PGC-1 $\alpha$ ) in A $\beta$ PP/PS1 transgenic mice, a preclinical model of AD, under a HFD [30]. HFD caused a dropdown of PGC- $1 \alpha$ levels, which was mediated by a decrease of phosphorylated cAMP response element-binding (p-CREB) protein levels [30]. The importance of these results is highlighted by the fact that PGC-1 $\alpha$ has a key role in the mitochondrial biogenesis process and, therefore, in the mitochondrial function, which is essential to neuronal activity. Our study also demonstrated acceleration in the process of memory loss in A $\beta P P / P S 1$ transgenic mice under a hypercaloric diet, as shown by short-term recognition memory values obtained in the novel object recognition test (NORT). This memory impairment was probably mediated by alterations in the brain IR and mitochondria [30]. Interestingly, a correlation between the down-regulation of PGC- $1 \alpha$ expression and $\mathrm{AD}$ has been also demonstrated, and the low expression of PGC- $1 \alpha$ in the brain of transgenic mice models of $\mathrm{AD}$ increases the formation of $A \beta$ through the increase in BACE1 activity across the amyloidogenic route [103-107]. Accordingly, Katsouri and co-workers reported that the stereotaxic administration of a lentiviral vector to express human PGC- $1 \alpha$ in the hippocampus and cortex of A $\beta P P 23$ transgenic mice improved memory and showed neuroprotective effects, hence demonstrating the efficacy of this gene therapy as a potential treatment of $\mathrm{AD}$ [104]. In turn, Martins and co-workers reported that HFD impairs memory in 3xTgAD mice. This cognitive alteration was associated with changes in mitochondrial energetic balances and loss of synaptic contacts [107]. Since synapses are sites of high-energy demand, some authors correlate the synaptic degeneration process with dysfunctional mitochondria, which are transported to synaptic terminals where high levels of ATP production are required [107].

In the same line, Sah and co-workers found that 3xTg mice fed with HFD suffered from memory impairment associated with a significant decrease in the expression of antioxidant enzymes, such as Heme oxygenase-1 (HO-1) and manganese-dependent superoxide dismutase (MnSOD), through the inactivation of protein kinase B (AKT)- Nuclear factor (erythroid-derived 2 (NRF2) signalling pathway [108]. Therefore, obesity decreases antioxidant enzymes required for brain neuroprotection.

On another front, results obtained by Lin et al. revealed that 5XFAD mice fed with HFD exhibited cognitive impairment and hippocampal oxidative stress. Cognitive impairment is also believed to occur due to decreased levels of brain-derived neurotrophic factor (BDNF), which is a central molecule in synaptic plasticity [109]. Furthermore, this study demonstrated that brain alterations are independent of peripheral metabolic alterations, since glucose tolerance was not impaired in the transgenic mice. In turn, Thériault and co-workers showed that the HFD induces deterioration on cognitive performance in AßPP/PS1 mice, which was associated with a decrease in the enzymatic activity of matrix metallopeptidase (MMP)-9 and a reduction of mRNA and protein levels of BDNF in the brain [110]. These results reinforce the hypothesis of a metabolic aetiology in the molecular basis of the development of $\mathrm{AD}$ at the preclinical level [111]. In addition, others demonstrated a down-regulation of hypothalamic BDNF protein levels in HFD-fed transgenic mice compared with wild type HFD-fed mice [112].

In summary, all these preclinical studies showed the existence of an initial memory impairment process associated to obesogenic diets, which could be partially explained by increased levels of soluble $A \beta$ and the inhibition of long term potentiation (LTP) linked to synapse loss. In addition, the down-regulation of BDNF levels mediated by PGC-1 $\alpha$, together with mitochondrial dysfunction, contribute to the decrease of synaptic connections, a marker that correlates with dementia in AD. Overall, these and other studies suggest that some improvement could be achieved through proper lifestyles, by avoiding metabolic alterations and designing therapies targeting one or some of these biomarkers.

\section{Are ceramides the bridge between peripheral type II diabetes and neurodegeneration in Alzheimer's disease?}

As discussed above, preclinical studies demonstrated that HFDs enhance cognitive loss, stressing its central effects. However, HFDs can also favour cognitive loss through peripheral alterations, specifically in the liver and adipose tissue. In an interesting study, Lyn-Cook and coworkers reported that HFDs induce liver damage (non-alcoholic steatohepatitis), by increasing the levels of pro-inflammatory cytokines (mainly TNFa) and ceramides [113]. Ceramides are toxic lipids which play key roles in brain oxidative stress, insulin resistance and cytoskeletal alterations, mechanisms involved in LOAD apparition [113]. In this respect, Dr. De la Monte suggested that chronic obesity induces insulin resistance associated with non-alcoholic steatohepatitis (NASH) [11-14, 113]. In addition, T2DM-related obesity increases hepatic insulin resistance, thus favouring inflammation and metabolic dysfunction, which leads to dysregulated lipolysis and the generation of ceramides [113]. A significant increase in ceramide levels promotes ER stress in the liver, which exacerbates insulin resistance, inflammation, and oxidative stress [11-13].

In addition to these peripheral harmful effects, ceramides originated in adipose tissue or in the liver reach the bloodstream and pass through the blood-brain barrier, exerting toxic effects in neurons [13]. In this respect, we hypothesize that ceramides in association with $A \beta \quad 1-42$ could exacerbate brain insulin resistance, oxidative stress, mitochondrial alterations and neuroinflamation. Thus, there could be a vicious circle between brain and peripheral tissues: peripheral damage would increase the risk of cognitive loss and the neurotoxic effects of $A \beta 1-42$ in the hypothalamus would lead to an altered regulation of peripheral metabolism [114-116]. This idea is supported by the fact that A $\beta$ 1-42 binds directly to the insulin receptor both in the periphery and in the hypothalamus, inducing a peripheral glucose intolerance and insulin resistance and eventually leading to T2DM [116]. Furthermore, it has been demonstrated that $A \beta$ 1-42 induces hepatic insulin resistance through the activation of the Janus Kinase 2 (JAK2) in a preclinical model of familial AD [99]. In addition to the liver, some authors have shown that amyloid can accumulate in other peripheral tissues such as pancreas and skeletal muscle $[117,118]$. Therefore, the A $\beta 1-42$ peptide originated at the brain may constitute a key factor involved in insulin resistance and T2DM [97].

Likewise, Shinohara and Sato proposed the involvement of an $\mathrm{X}$ Factor underlying the bidirectional interactions between diabetes and LOAD. Hence, they suggest the existence of a vicious circle between diabetes and LOAD, which could be initiated by peripheral ceramides [119]. According to this idea, the authors put forward a potential equation where Aß1-42 levels would be multiplied by an X factor. This unknown factor could be ceramides, which may amplify the neurotoxicity of A $31-42$ peptide. Consequently, cognitive loss could be prevented by breaking this circle, and antidiabetic treatments could be beneficial against LOAD.

\section{Endoplasmic reticulum (ER) stress: a link between obesity and cognitive loss}

Some research studies have indicated that the ER stress is involved in the appearance of degenerative diseases in the brain [120,121]. Obesity seems to exacerbate this situation, favouring cognitive loss and promoting AD-like neuropathology [122-125]. As we have discussed above, the accumulation of disease-specific misfolded proteins is a hallmark of $\mathrm{AD}$, and $\mathrm{ER}$ could have a key role in this process.

In eukaryotic cells, such as neurons, the ER is a cellular compartment involved in calcium homeostasis, lipid biosynthesis and protein folding and maturation. Under normal physiological conditions, ER activity is paramount for most cellular mechanisms. Glucose-regulated 
protein 78 or binding immunoglobulin protein (GRP78/BiP) molecules are bound to three different ER transmembrane receptor proteins, known as the PKR-like endoplasmic reticulum kinase (PERK), inositol requiring enzyme 1 (IRE1 $\alpha$ ) and activating transcription factor 6 (ATF6) [122]. Under ER stress, there is a release of BiP, which triggers the activation of ER stress response. The activation of PERK pathway leads to a signalling cascade which begins with the phosphorylation of the eukaryotic initiation factor 2 alpha (eIF2 $\alpha$ ) and eventually attenuates global protein synthesis [125]. Subsequently, this signalling pathway also promotes the activation of several downstream proteins like the activating transcription factor 4 (ATF4), proapoptotic C/EBP homologous protein (CHOP) and growth arrest and DNA damage-inducible protein $34 \mathrm{KDa}$ (GADD34) [121,122].

In neurons, an appropriate ER response is necessary for the control of protein synthesis and synaptic and neuronal function [125-127]. In $\mathrm{AD}$, alterations in this response could lead to defects to long-term memory formation. Specifically, disruptions on the homeostasis of protein folding lead to the accumulation of misfolded proteins in the ER and upregulation of proapoptotic proteins like CHOP [124]. Hence, conditions inducing a sustained brain ER stress and leading to activation of the unfolded protein response (UPR), such as obesity, could clearly result in deleterious effects, although the underlying mechanisms are still not well understood. Some research groups have reported that palmitate could be one of the elements responsible for the activation of these mechanisms in mice under HFD [128]. Thus, it was hypothesised that the association of palmitate and $A \beta$ could increase even further the burden on the ER (Fig. 3) [129,130].

Other previous studies have shown that phosphorylation of eIF $2 \alpha$ is increased in the hipocampus of preclinical mice models of AD. For instance, O'Connor and coworkers reported that PERK-eIF2 $\alpha$ signalling activation increases $A \beta P P$ processing and $A \beta$ formation via direct upregulation of BACE-1 [126]. This data was replicated in the 5XFAD mice model by other groups, which also combined heterogeneous knockouts for $\mathrm{PERK}^{+/-}$and the $5 \times \mathrm{XFA}$ transgenic model (PERK haploinsufficiency) [131-133]. The results showed improvements in memory deficits in $\mathrm{PERK}^{+/-}$mice compared with 5xFAD mice. Furthermore, under insulin-deficiency conditions, PERK-eIF2 $\alpha$ ER stress signalling pathway is dramatically activated in the brain of 5XFAD mice, thus increasing $\mathrm{AD}$ risk [133]. Likewise, the PERK pathway effector ATF4 is a repressor of CREB [121], which is required for synaptic plasticity as well as for learning processes.

Complementarity, eIF2 $\alpha$ could also be phosphorylated by three different kinases associated with stressors. These kinases are the RNAactivated protein kinase (PKR), the heme-regulated inhibitor kinase (HRI) and the general control non-depressible 2 kinase (GCN2) $[87,88,134]$. They belong to the integrated stress response (ISR) and some of them have been linked to synapse loss and cognitive deficits in human and preclinical mice models of AD. For example, Mouton-Liger et al. reported that in human $\mathrm{AD}$ brains there is significant correlation between increase in PKR and BACE1 protein levels [135]. Strangely, Hwang and co-workers reported that PKR inhibition improves memory without affecting $A \beta$ load in the hippocampus in 12-month-old 5xFAD mice [130]. The authors concluded that this PKR inhibition without affecting $A \beta$ levels might provide a promising alternative strategy for developing a potential AD treatment. In another study, Ma and coworkers crossed PERK and GCN2 knockouts with AßPP/PS1 transgenic mice. They observed that eliminating either enzyme reduced brain levels of $A \beta$ and prevented memory deficits associated with the A $\beta P P /$ PS1 phenotype [136].

On another research line, Sims-Robinson and co-workers evidenced an increase of ER stress activation on the hippocampus of B6-HF mice fed with HFD. They concluded that this was due to an inhibition of the IR signalling, probably mediated through the activation of the c-Jun Nterminal kinases (JNKs), which are direct inhibitors of the IR substrate 1 (IRS1) [137]. Indeed, an increase in the phosphorylation rates of serine amino acids of the IRS1 would induce desensitization of the hippocampal IR and it is believed that the JNK1 isoform plays a prominent role in this mechanism [138]. In the same line, Liang and coworkers demonstrated a significant increase in the phosphorylation of both PERK and eIF2 $\alpha$, as well as IRE1 $\alpha$ and JNK, in hippocampus and frontal cortex of HFD rats [139]. Therefore, they concluded that UPR activation was increased in the brain of obese rats, and that this mechanism was involved in insulin resistance and cognitive loss through JNKs activation and IRS1 inhibitory phosphorylation. This data supports the metabolic hypothesis of the appearance of cognitive deficits independent of $\mathrm{A} \beta$ production.

The administration of ursolic acid is a potential strategy to find a therapeutic approach for these alterations. This natural triterpenoid compound exerts many pharmacological actions such as anti-oxidant, anti-inflammatory and anti-tumoral effects. Thus, Lu and co-workers demonstrated that ursolic acid has a protective effect preventing ER activation in the hippocampus, hence improving cognitive responsiveness [128]. Furthermore, quercetin, a polyphenolic flavonoid compound present in a variety of fruits and vegetables, exerts beneficial effects on obesity and cognitive processes by preventing the activation of PERK-eIF2 $\alpha$ signalling pathway and avoiding phosphorylation of ATF4 through GADD34 induction [140,141]. Likewise, it has been shown that the administration of the polyunsaturated fatty acid $\alpha$-linolenic acid to aged female Sprague-Dawley rats fed with a HFD improved the cognitive process [142]. Its beneficial effects are mediated by the inhibition of UPR response through the down-regulation of brain ATF4 levels, thus leading to the increase of p-CREB phosphorylation rates [142].

\section{Synaptic loss mediated by neuroinflammation in obesity}

Obesity has been associated with chronic inflammatory processes derived from the activity of hypertrophic adipocytes, free fatty acids and reactive oxygen species [143-145]. In the CNS, microglia have significant roles in the control of these mechanisms.

Under physiological conditions, microglial cells present a branched morphology and are responsible for the production of anti-inflammatory and neurotrophic factors (inactive or unreactive state (M2) [146]. However, in some conditions such as obesity, microglial cells become reactive and change their morphology to amoeboid. This is followed by an enhancement of pro-inflammatory responses, both on microglia itself and in other cells such as astrocytes, through the release

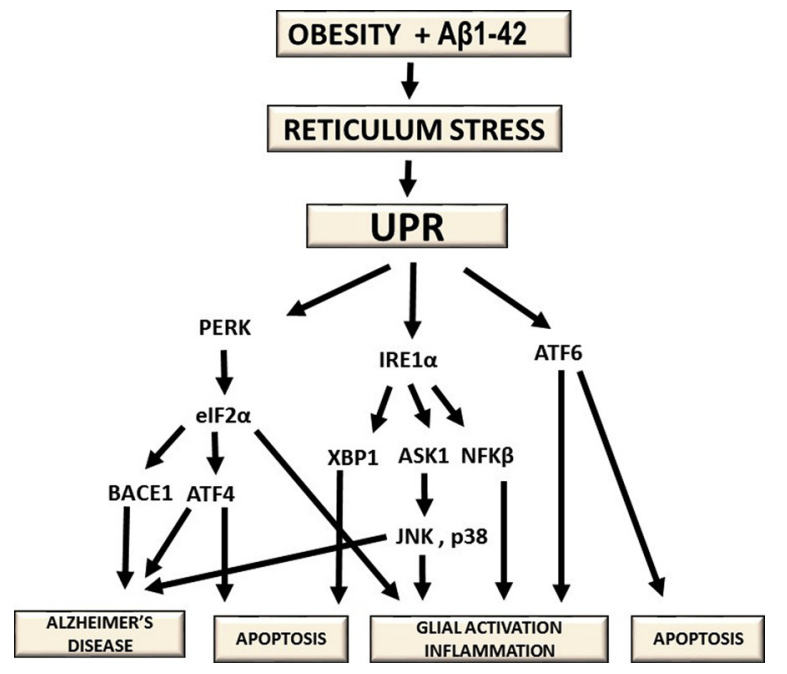

Fig. 3. Chain of events relating obesity alterations, the accumulation of A $\beta 1-42$ and the stress on the reticulum. Activating stimuli on the ER cause release of $\mathrm{BiP}$ and the initiation of UPR signalling. These mechanisms have been related to the appearance of pathologies like AD through the upregulation of apoptotic and glial reactivity biomarkers. 
of certain cytokines (M1 state) [147]. Eventually, M1 microglia and astrocytic activity lead to neuronal death and pathologies like AD $[148,149]$. These assumptions have been supported by a meta-analysis of cytokines, which revealed increased concentrations of interleukin 6 (IL-6) and tumor necrosis factor $\alpha$ (TNF $\alpha$ ) in peripheral blood of $\mathrm{AD}$ patients [150].

As discussed above, when any of the pathways of the UPR activates, there is an up-regulation of nuclear factor kappa-light-chain-enhancer of activated B cells (NF-kB), a key modulator of pro-inflammatory genes [151]. Likewise, several studies indicate that inflammation and abnormal ER activity are critical events in the establishment of hypothalamic and peripheral insulin resistance in metabolic disorders. Thus, in animal models of T2DM and obesity, inflammation in the hypothalamus is an important part of the underlying pathogenic mechanism, especially the activation of TNF- $\alpha$ and the kinase inhibitor of nuclear factor kappa-B kinase subunit beta (IKK $\beta$ )/NF-kB signalling axis $[87,88,116,152]$. Specifically, under a HFD, IKK $\beta$ becomes activated and phosphorylates IRS1 inhibitory serine sites, resulting in a desensitization of IR signalling [57]. In addition, cortical and hippocampal dysfunction seems to share common pathways in AD.

JNKs constitute another important element regulating inflammation and IR. JNKs pathways control several processes, including insulin resistance in peripheral tissues, such as liver or pancreas, and also in the brain [153-155]. Usually, these pathways are upregulated by cytokines and ER stress. Hence, it is known that neuroinflammation increases brain levels of TNF $\alpha$, which activates JNKs -mainly JNK1- and leads to a decline of insulin signalling [56,57]. In addition, the activation of ER/ UPR response, specifically IRE1 $\alpha$ pathway, triggers the splicing of Xbox binding protein 1 (XBP1) mRNA. The products of this splicing also activate JNK. This process has important effects on the development of apoptotic processes accounting for cognitive decline [156]. Additionally, IRE1 $\alpha$ can also be phosphorylated by JNKs, leading to a recruitment of tumour necrosis factor receptor associated factor-2 (TRAF2), which would enhance further apoptotic responses through caspase 12. Therefore, it seems that the UPR and JNKs are both involved in neuronal apoptosis processes, which are favoured by obesity [125,152].

Interestingly, the expression of protein-tyrosine phosphatase $1 \mathrm{~B}$ (PTP1B) also becomes up-regulated in obesity models using HFD [157]. This phosphatase is located in the ER membrane and it is a major negative regulator of insulin, leptin and BDNF receptors (Tyrosine Receptor Kinase B; TRKB). Under physiologic conditions, the upregulation of PTP1B is promoted by TNF $\alpha$ and it has significant effects on cognition and memory formation. Elevated levels of PTP1B dephosphorylate tyrosine residues and inhibit downstream signal transduction of the previously mentioned receptors, but activate microglia [158]. In addition, it has been demonstrated that PTP1B is a regulator of the UPR response through the modulation of PERK/eIF1 $\alpha$ signalling in peripheral and neuronal cell culture studies [157]. Likewise, PTP1B inhibition attenuates neuronal toxicity in the ER mediated by the mitochondrial neurotoxin rotenone and tunicamycin [159].

Finally, soluble $A \beta$ peptide oligomers can activate microglial cells and increase TNF- $\alpha$ brain levels $[56,57]$. Therefore, obesity and A $\beta$ can together overstimulate an aberrant TNF $\alpha$ signalling, leading to activation of the stress kinases that block insulin signalling in the brain. Following this line of thought, obesity and neurodegeneration may run in parallel in a complex mechanism where the activation of NF-kB would lead to the expression of inflammatory cytokines, hence promoting a neuroinflammatory state.

\section{Pharmacological approaches for metabolic late onset Alzheimer's disease treatment}

According to the metabolic hypothesis of $\mathrm{AD}$, therapies capable of restoring normal brain insulin signalling in the CNS may have beneficial effects on brain function. In this sense, a growing body of evidence suggest that insulin receptor have multiple brain functions related to cognition, neuroprotection through the activation of Akt, modulation of $\mathrm{A} \beta \mathrm{PP}$ and $\mathrm{A} \beta$ levels, neuroinflammation and synapsis formation. Hence, brain insulin dysregulation could contribute to $\mathrm{AD}$ pathogenesis, and drugs involved in the modulation of insulin receptor could have potential application in the treatment of AD. This could be achieved not only by improving brain cognition at the hippocampal level, but also modulating the hypothalamus and peripheral tissues such as the liver, which would improve metabolic diseases such as T2DM. Consequently, bearing in mind that $\mathrm{AD}$ can be considered a metabolic alteration, its treatment should not only focus in brain processes such as memory, but also in peripheral organs related to insulin resistance (Table 1).

\subsection{Intranasal insulin}

Mao and co-workers reported that the administration of intranasal insulin for 6 weeks in A $\beta$ PP/PS1 mice improves cognitive function by activating non-amyloidogenic pathways that favour a decrease in brain $\mathrm{A} \beta$ levels and $\mathrm{A} \beta$ plaque deposits [160]. Therefore, activation of brain insulin receptors improves $A \beta$ pathology at preclinical level and intranasal insulin may be a potential strategy to modify the course of $\mathrm{AD}$ (Table 1).

Several clinical studies have also examined the effects of intranasaladministered insulin in $\mathrm{AD}$ patients. For instance, Craft and co-workers

Table 1

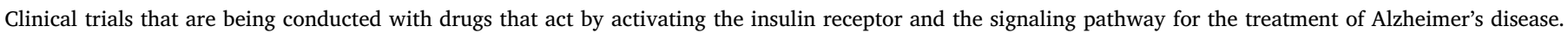

\begin{tabular}{|c|c|c|c|}
\hline Drug & Phase & CT number & Disease \\
\hline Rosiglitazone & II & NCT00381238 & Mild to moderate $\mathrm{AD}$ \\
\hline Rosiglitazone & II & NCT00334568 & Examine the drug response in patients with $\mathrm{AD}$ \\
\hline Rosiglitazone & I & NCT00688207 & $\mathrm{AD}$ (the study is designed to assess the pharmacokinetics of Rosiglitazone) \\
\hline Rosiglitazone & III & NCT00428090 & Mild To Moderate AD \\
\hline Rosiglitazone & III & NCT00550420 & Mild to moderate $\mathrm{AD}$ \\
\hline Rosiglitazone & III & NCT00348309 & Mild to moderate $\mathrm{AD}$ \\
\hline Pioglitazone & II & NCT00982202 & $\mathrm{AD}$ \\
\hline Pioglitazone & III & NCT01931566 & Mild to moderate $\mathrm{AD}$ \\
\hline Pioglitazone & III & NCT02284906 & $\mathrm{AD}$ \\
\hline Intranasal Insulin Glulisine & II & NCT01436045 & Mild To Moderate AD \\
\hline Intranasal insulin detemir & II & NCT01595646 & $\mathrm{AD}$ or amnestic mild cognitive impairment \\
\hline Metformin & II & NCT00620191 & Amnestic Mild Cognitive Impairment \\
\hline Liraglutide & Not Applicable & NCT01469351 & $\mathrm{AD}$ \\
\hline Exendin-4 & II & NCT01255163 & $\mathrm{AD}$ \\
\hline Exendin-4 & III & NCT02847403 & Cognitive Decline in Dysglycemic Patients \\
\hline HM15211 & I & NCT03374241 & Obesity \\
\hline GIP/GLP-1 Co-Activity & Not Applicable & NCT03526289 & Overweight and Type 2 Diabetes \\
\hline Insulin & & NCT00438568 & Mild To Moderate AD \\
\hline
\end{tabular}


evaluated the effects of intranasal administrations of either insulin (10 or 20 IU twice a day for a total dose of 20 or 40 IU per day) or placebo (saline twice a day) for 4 months in AD patients (clinical trial number NCT00438568) [161,162]. They assessed changes in cognitive parameters, brain glucose metabolism and $A \beta$ levels in cerebrospinal fluid (CSF). The results of the trial suggested that the administration of intranasal insulin could improve cognition and brain glucose metabolism in patients with mild cognitive impairment or AD.

After the potential positive effects of intranasal insulin in $\mathrm{AD}$, different pharmaceutical preparations of insulin have been developed to improve its bioavailability. For example, insulin detemir incorporates fatty acids to its chemical structure, thus increasing its binding to albumin and allowing a slower elimination, which lengthens its half-life [162]. Craft and co-workers reported that the positive effects of insulin detemir on memory are associated with an increased volume in brain regions affected by AD neuropathology [162]. However, the authors reported that the efficacy of insulin detemir decreased over longer-term administration in these patients, whereas regular insulin continued to provide beneficial effects on memory. The explanation of these results is still unclear, although it has been proposed that long-acting insulins may desensitize the insulin receptor and thereby increase insulin resistance [56].

Finally, is worth to mention that cognitive processes in AD patients are influenced by gender and APOE4. Interestingly, cognition function in APOE4-negative patients is usually improved after intranasal insulin, while APOE4-positive $\mathrm{AD}$ patients showed contradictory results [26,163]. Likewise, men respond better to insulin than women [26].

\subsection{Incretins}

This group includes some synthetic long-acting analogs such as Glucagon-like peptide-1 (GLP-1), receptor agonists such as exendin-4, as well as liraglutide and lixisenatide, which possess insulinotropic activity, among others.

At preclinical level, intraperitoneally administration of liraglutide or lixisenatide improves neuropathological markers of $\mathrm{AD}$, such as decrease in the number of plaques and glial activation, and also improves cognition parameters in AßPPSwe/PS1dE9 mice [164]. However, several clinical studies are now evaluating the potential efficacy and safety of GLP-1 mimetics in AD, such as liraglutide. For instance, the clinical trial NCT01469351 evaluated the efficacy of liraglutide in AD patients, reporting that 6-month treatment with this drug improved brain glucose metabolism with a slight improvement on cognition (Table 1). Another clinical study, the NCT02140983, evaluated the effects of liraglutide on memory and attention of elder patients with insulin resistance. Worth to mention, the patients had pre-diabetes and half of all subjects had a family history of dementia. However, no data from this study has been reported yet. Exendin- 4 is another incretin-mimetic long-acting GLP-1 receptor agonist approved for T2DM treatment, which also have shown neuroprotective effects in preclinical models of AD [165]. Unfortunately, clinical trials with exendin-4 in early-stage AD, such as NCT01255163, did not reported beneficial effects on cognition.

Likewise, glucose-dependent insulinotropic polypeptide (GIP) analogues such as D-Ala2-GIP also showed neuroprotective effects on synaptic plasticity and cognition in animal models. Thus, it has been reported that these compound significantly reduces $A \beta 42$ plaques and neuroinflammation in preclinical AD mice models [166]. Since these peptides were effective at the preclinical level, the next strategy was the development of dual peptide agonists GLP-1/glucagon and GLP-1/GIP combined. Moreover, triagonists GLP-1/GCG/GIP are in early stages of development. Thus far, two studies in murine AD models have reported that triple agonists improve cognitive processes by increasing BDNF levels and p-CREB signalling pathway, and by decreasing plaques and neuroinflammation [167]. However, most research studies with triagonists have been carried out in metabolic disorders such as T2DM and obesity, where they are more effective than the single administration of each peptide alone. Regarding clinical studies, only the triagonist HM15211 is under investigation as a treatment for obesity (NCT03374241). In this sense, the next aim is to evaluate the efficacy of this triagonist, which integrates the actions of the three endogenous hormones, in T2DM and weight decrease, as well as in other potential diseases.

\subsection{Metformin}

It has been shown that the anti-diabetic drug metformin is effective in preclinical models of $\mathrm{AD}$ [168]. Thus, Ou and co-workers reported that metformin improves cognitive process, decrease the $\mathrm{A} \beta$ production and neuroinflammatory response in the hippocampus of A $\beta P P / P S 1$ mice [169]. The authors suggested that the neuroprotective effects of metformin are mediated by the modulation of the AMPK/mTOR/S6K/ BACE1 pathway. However, these neuroprotective benefits of metformin in AD are contradictory, since a recent study in transgenic models of tauopathy with cognitive deficits has shown that metformin can aggravate the risk of tauopathy in diabetic patients [170].

In turn, Infante-Garcia and co-workers studied in a mixed murine model of AD and T2DM (AßPP/PS1x db/db mice) the effects of the antiT2DM polypill (PP), which contains several drugs used to treat T2DM, including metformin, aspirin, a generic statin, and an angiotensinconverting enzyme inhibitor [171]. They reported that PP could be a suitable strategy for the treatment of serious complications of T2DM, such as cognitive alterations.

Recently, Koenig and co-workers published the results of a clinical trial with metformin (NCT01965756) in AD patients with mild cognitive impairment or mild dementia. They reported that metformin slightly improved learning and memory processes [172]. In another clinical trial (NCT00620191), the effects of metformin in Amnestic Mild Cognitive Impairment (MCI) were evaluated. Specifically, the aim of this study was to assess the changes in a memory and general cognitive function test (the Alzheimer's Disease Assessment Scale-cognitive subscale-ADAS-Cog used in clinical trials.). The study also aimed to compare brain function through mean changes in PET scan between the patients treated with metformin and those treated with placebo. So far, no results from this study have been reported yet.

\subsection{Thiazolidinediones}

Thiazolidinediones are agonists of peroxisome-proliferator activated receptors (PPARs). They possess antidiabetic activity and have also shown neuroprotective effects in preclinical models of AD [48]. These compounds are nuclear hormone receptors that induce physiological responses through the regulation of gene expression, and they are involved in the metabolic regulation of carbohydrates, proteins and lipids. They also reduce neuroinflammation by inhibiting glial activation, since it has been reported that rosiglitazone significantly improves cognition in rats after $A \beta$ injection in the hippocampus through inhibition of microglial cytokine release [173]. According to these results, the regulation of microglia constitutes a key target involved in cognitive improvement in preclinical AD models.

Regarding the use of rosiglitazone in clinical studies, Gold and colleagues reported that administration of 2-mg or 8-mg of this compound during 24 weeks in APOE- $\varepsilon 4$ negative patients does not show any statistical difference when compared to placebo treatment [174]. The current clinical study NCT00334568 aims to evaluate the effects of rosiglitazone on i) cerebral glucose utilization measured by [18F] FDG uptake and ii) cognitive process in $\mathrm{AD}$. No results have been reported yet. In turn, the study NCT00348309 assessed the effects of a 54-week treatment of rosiglitazone (extended release tablets) combined with donepezil on cognitive parameters of patients with mild to moderate AD. Again, no clinical improvement was achieved with this treatment [175]. 
On another front, previous studies have reported neuroprotective effects of pioglitazone in preclinical models of $\mathrm{AD}$, through a decrease in neuroinflammation and also in mRNA and protein levesl of BACE1 [176]. This compound was able to significantly decrease the cerebral $A \beta$ levels, and could hence constitute a potential drug with the capacity to modify the course of the disease. Interestingly, Fernandez-Martos and co-workers reported that acute 2-week treatment with combined leptin and pioglitazone improves cognition and decrease neuropathological parameters of AD in A PPP/PS1 mice [177]. In turn, Geldmacher and colleagues evaluated the safety of long-term treatment with pioglitazone (15-mg tablets) in elderly nondiabetic AD patients [178]. The authors reported that pioglitazone was well tolerated and safe during the 18-month treatment trial. In the same line, the NCT01931566 study evaluated the effects of pioglitazone compared with placebo in $\mathrm{AD}$ patients with mild cognitive impairment (MCI). The aim of this study was to delay the onset of memory loss in cognitively normal participants who were at high-risk for developing MCI within the next 5 years. Currently, no results have been reported. However, the clinical trial NCT02284906 aims to evaluate the safety and effectiveness of pioglitazone on cognitive function in participants who have completed the previous study.

Regarding thiazolidinediones, we can summarize that, in spite the promising results observed in preclinical studies, no clinical study has reported successful results yet [179-181]. Therefore, additional clinical studies with PPAR $\gamma$ agonists are still required, either in monotherapy or in combination with other drugs, in order to evaluate the efficacy in improving brain insulin/IGF-1 resistance and thus improving cognition and preventing neurodegeneration in initial stages of $\mathrm{AD}$.

\section{5. c-Jun-N-terminal kinase inhibitors}

Although SP600125 is the best characterized inhibitor of JNK activity, its application has been impeded by its low target selectivity, and the clinical efficacy of this compound is also limited by its poor aqueous solubility [157].

Chalcones are phenolic naturally compounds highly widespread in fruits, vegetables, spices, tea and soy-based foodstuff. Some of these compounds have been shown to inhibit JNK pathway and they are considered important secondary metabolites, precursors of flavonoids and isoflavonoids in plants [182]. Moreover, these molecules are interesting due to their simple chemistry, easy synthetic procedures, multiplicity of substitutions and diverse pharmacological potentials, such as anti-cancer, antioxidants, anti-inflammatory, adenosine receptor ligands, antimalarial, antimicrobial, anti-HIV or anti-protozoal [183-187]. Over the years, different chalcones have been isolated, such as isoliquiritigenin, echinatin, licochalcone A (Lic-A), licochalcone C and licochalcone E (Lic-E).

Lic-E exhibits cytotoxicity to human tumor cell lines and endothelial cells, as well as cutaneous anti-inflammatory potential [186]. Moreover, Lic-E activates the NRF2-Antioxidant Response Element (ARE) system and up-regulates downstream NAD (P) H: quinone oxidoreductase 1 (NQO1) and HO-1, suggesting a therapeutically relevant effect to oxidative-stress-related neurodegeneration [182]. In addition, it has been evidenced that Lic-E has a neuroprotective effect against 1methyl-4-phenyl-1,2,3,6-tetrahydropyridine (MPTP), which induces nigrostriatal dopaminergic neurodegeneration in mice [186].

Lic-A could be a promising molecule for the treatment of obesityderived complications associated with cognitive impairment. It is one of the major bioactive constituents of the roots of liquorice and it has been shown to have anti-inflammatory and anti-microbial activities, as well as anti-tumour effects $[187,188]$. Lic-A is a specific inhibitor of JNK1 and studies using JNK1 knockout mice revealed that these animals showed lower body weight and increased insulin sensitivity [(Busquets et al. 2018). Moreover, Lic-A has been identified as a PTP1B inhibitor, hence increasing its potential effect for the treatment of T2DM at peripheral level and enhancing the cognitive process in the brain. Of note, our group has reported beneficial effects of this molecule in a murine model of epilepsy [135,184,185], by demontsrating that JNK1 inhibition by Lic-A reduced cell death derived of excitotoxic damage, as well as neuroinflammation.

Additionally, several research studies have synthesized and evaluated hydroxychalcones as inhibitors of human acetylcholinesterase. These new compounds were found to be effective and could be potential new disease-modifying drug candidates for the treatment of AD. Thus, Jeon and co-workers synthesized hydroxychalcones with potent BACE1 inhibiting effect, preventing the formation of insoluble $A \beta$

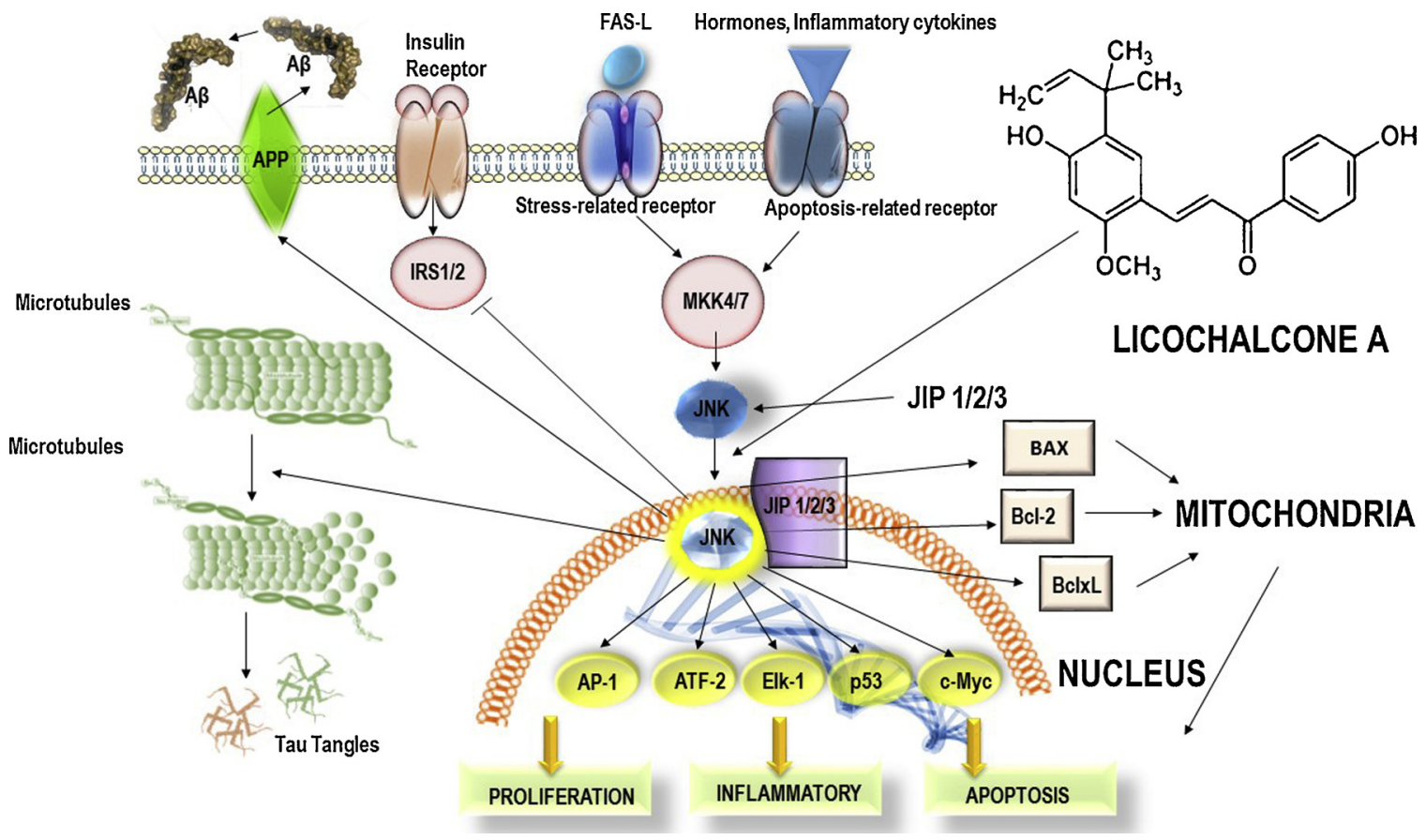

Fig. 4. Graphical representation of some of the mechanisms described. JNKs are mediators of proliferative, inflammatory and apoptotic mechanisms. Lic-A, a chalcone extracted of liquorice roots, behaves as a specific inhibitor of the JNK1. 
peptide, as well as inhibition of MAPK signalling and TAU phosphorylation [186,187]. In addition, novel selective water-soluble and brainpenetrant JNK inhibitors have been tested [188]. Likewise, some experiments have evaluated the effects of i.p. and i.c.v. administrations of SR11935 and SR3306, brain-penetrant JNK2/3 isoform-selective inhibitors [188]. The results showed similar anorectic effects for both isoforms, suggesting that JNK2 and JNK3 mediate aspects of the anorectic effect observed in pan-JNK inhibition.

\section{Concluding remarks}

It has been described that obesity enhances the loss of neurons [189]. Therefore, it is paramount to investigate how this condition is associated with soluble $A \beta$ and how it promotes age-related pathologies $[190,191]$. Ceramides are generated in peripheral tissues during the obesogenic process. In the brain, these toxic lipids could amplify and potentiate the neurotoxic effects of A $\beta 1-42$ [192]. Hence, drugs with antidiabetic peripheral effects are expected to be capable of preventing the cognitive loss in LOAD, by inhibiting the enhancing effects of ceramides on Aß1-42 [193-199].

In addition to obesity and altered insulin receptor activity, there is mounting data pointing to ER strees and neuroinflammation as key mechanisms in sporadic AD development [200]. Indeed, obesity causes ER stress by promoting a pro-inflammatory state through the activation of molecules like PTP1B and JNK, as well as by increasing A $\beta$ levels through BACE1 activation in the amyloidogenic pathway [201,202]. Moreover, PTP1B and JNK are also relevant in the regulation of IR signalling, pleading to its inhibition and the appearance of insulin resistance. In this sense, JNKs emerge as molecular targets that could restore homeostasis alterations related to insulin resistance, ER stress and neuroinflammation [203-205]. In order to modulate these mechanisms, different pharmacological approaches that may act in a combined and, potentially, synergistic manner have been proposed. Efforts should be addressed to achieve a better understanding of the precise role of each JNK isoforms in brain and during cognitive impairment, as well as to test effective and specific pharmacological inhibitors.

Finally, drugs modulating one or several of these mechanisms could be a pharmacological strategy to prevent $\mathrm{AD}$. Licochalcones are potential candidates, since these compounds have shown different neuroprotective properties. Specially, Lic-A is a promising compound due to its inhibitory activity on JNK1 and PTP1B [203-205]. Thus, Lic-A is capable of reducing neuroinflammation and insulin resistance, two of the pathological hallmarks of sporadic cognitive loss related to $\mathrm{AD}$ (Fig. 4). Likewise, preclinical studies and clinical trials indicate that the intranasal administration of insulin, the administration of incretins and other antidiabetic drugs can also have a therapeutic application in the prevention of AD [206-214]. However, as to other diseases such as AIDS or the prevention of coronary heart disease, a combined treatment could be necessary for the successful treatment of AD.

\section{Conflict of interest}

The authors do not have any current or potential conflict of interest, including any financial, personal or other relationships with other people or organizations. All authors have reviewed the contents of the manuscript being submitted and approved its content.

\section{Acknowledgements}

This work was supported by the Spanish Ministry of Science and InnovationSAF2017-84283-R, PI2016/01, CB06/05/0024 (CIBERNED), the European Regional Development Founds and MAT2014-59134-R project. NIA 1R15AG050292 from Generalitat de Catalunya. Research team from UB and URV belongs to 2014SGR-525 from Generalitat de Catalunya. ESL and MLG belong to 2014SGR-1023. CBZ is supported by grants from CONACyT Mexico (No. 0177594) and RDCT from Postdoctoral fellowship CONACYT No. 298337 and the Doctoral Program in Sciences in Molecular Biology in Medicine, LGAC Molecular Bases of Chronic Diseases-Degenerative and it's Applications (000091, PNPC, CONACyT).

\section{References}

[1] A. Alzheimer, Über eine eigenartige Erkrankung der Hirnrinde, Allgemeine Zeitschrift Fur Psychiatrie Und Psychisch-Gerichtliche Medizin 64 (1907) $146-148$.

[2] J. Hardy, N. Bogdanovic, B. Winblad, E. Portelius, N. Andreasen, A. CedazoMinguez, H. Zetterberg, Pathways to Alzheimer's disease, J. Intern. Med. 275 (2014) 296-303.

[3] N. Nukina, Y. Ihara, One of the antigenic determinants of paired helical filaments is related to tau protein, J. Biochem 99 (1986) 1541-1544.

[4] H. Zempel, E. Mandelkow, Lost after translation: missorting of tau protein and consequences for Alzheimer disease, Trends Neurosci. 37 (2014) 721-732.

[5] C.A. Lane, J. Hardy, J.M. Schott, Alzheimer's disease, Eur. J. Neurol. 25 (2018) 59-70.

[6] M.A. Pericak-Vance, J.L. Haines, Genetic susceptibility to Alzheimer disease, Trends Genetics 11 (1995) 504-508.

[7] S. Craft, Insulin resistance syndrome and Alzheimer's disease: age- and obesityrelated effects on memory, amyloid, and inflammation, Neurobiol Aging, Suppl. 1 (2005) 65-69.

[8] P.G. Ridge, R.B. Hoyt, K. Boehme, S. Mukherjee, P.K. Crane, J.L. Haines, R. Mayeux, L.A. Farrer, M.A. Pericak-Vance, G.D. Schellenberg, J.S.K. Kauwe, Alzheimer's disease genetics consortium (ADGC). Assessment of the genetic variance of late-onset Alzheimer's disease, Neurobiol. Aging 41 (2016) 200 E13200.e20.

[9] S. Craft, E. Peskind, M.W. Schwartz, G.D. Schellenberg, M. Raskind, Jr.D. Porte, Cerebrospinal fluid and plasma insulin levels in Alzheimer's disease: relationship to severity of dementia and apolipoprotein E genotype, Neurology 50 (1998) $164-168$.

[10] V.A. Moser, C.J. Pike, Obesity accelerates Alzheimer-related pathology in APOE4 but not APOE3 mice, eNeuro 13 (2017) 4.

[11] S.M. de la Monte, Insulin resistance and neurodegeneration: progress towards the Development of New therapeutics for Alzheimer's disease, Drugs 77 (2017) 47-65.

[12] S.M. de la Monte, Insulin resistance and Alzheimer's disease, BMB Rep. 42 (2009) 475-481.

[13] S.M. de la Monte, Type 3 diabetes is sporadic Alzheimer's disease: mini-review, Eur. Neuropsychopharmacol. 24 (2014) 1954-1960.

[14] S.M. De la Monte, M. Tong, N. Lester-Coll, M. Plater Jr, J.R. Wands, Therapeutic rescue of neurodegeneration in experimental type 3 diabetes: relevance to Alzheimer's disease, J. Alzheimer's Dis. 10 (2006) 89-109.

[15] R.A. DeFronzo, E. Ferrannini, L. Groop, R.R. Henry, W.H. Herman, J.J. Holst, F.B. Hu, C.R. Kahn, I. Raz, G.I. Shulman, D.C. Simonson, M.A. Testa, R. Weiss, Type 2 diabetes mellitus, Nat. Rev. Dis. Primers 1 (2015) 15019.

[16] M. Ben Nasr, F. D'Addi, V. Usuelli, S. Tezza, R. Abdi, P. Fiorina, The rise, fall, and resurgence of immunotherapy in type 1 diabetes, Pharmacol. Res. 98 (2015) 31-38.

[17] R. Bassi, P. Fiorina, Impact of islet transplantation on diabetes complications and quality of life, Curr. Diab. Rep. 11 (2011) 355-363.

[18] M. Hokama, S. Oka, J. Leon, T. Ninomiya, H. Honda, K. Sasaki, T. Iwaki, T. Ohara, T. Sasaki, F.M. LaFerla, Y. Kiyohara, Y. Nakabeppu, Altered expression of diabetesrelated genes in Alzheimer's disease brains: Hisayama study, Cereb. Cortex 24 (2014) 2476-2488.

[19] S. Kang, Y.H. Lee, J.E. Lee, Metabolism-centric overview of the pathogenesis of Alzheimer's disease, Yonsei Med. J. 58 (2017) 479-488.

[20] W.Q. Zhao, M. Townsend, Insulin resistance and amyloidogenesis as common molecular foundation for type 2 diabetes and Alzheimer's disease, Biochim. Biophys. Acta 1792 (2009) 482-496.

[21] Y.F. Chuang, Y. An, M. Bilgel, D.F. Wong, J.C. Troncoso, R.J. O’Brien, J.C. Breitner, L. Ferruci, S.M. Resnick, M. Thambisetty, Midlife adiposity predicts earlier onset of Alzheimer's dementia, neuropathology and presymptomatic cerebral amyloid accumulation, Mol. Psychiatry 21 (2016) 910-915.

[22] L. Devi, M.J. Alldred, S.D. Ginsberg, M. Ohno, Mechanisms underlying insulin deficiency-induced acceleration of $\beta$-amyloidosis in a mouse model of Alzheimer's disease, PLoS One 7 (2012) e32792.

[23] S.M. De la Monte, Therapeutic targets of brain insulin resistance in sporadic Alzheimer's disease, Front. Biosci. 4 (2012) 1582-1605.

[24] C.A. Grillo, G.G. Piroli, R.C. Lawrence, S.A. Wrighten, A.J. Green, S.P. Wilson, R.R. Sakai, S.J. Kelly, M.A. Wilson, D.D. Mott, L.P. Reagan, Hippocampal insulin resistance impairs spatial learning and synaptic plasticity, Diabetes 64 (2015) 3927-3936.

[25] E.M. Ribe, S. Lovestone, Insulin signalling in Alzheimer's disease and diabetes: from epidemiology to molecular links, J. Intern. Med. 280 (2016) 430-442.

[26] N. Zhao, C.C. Liu, A.J. Van Ingelgom, Y.A. Martens, C. Linares, J.A. Knight, M.M. Painter, P.M. Sullivan, G. Bu, Apolipoprotein E4 impairs neuronal insulin signaling by trapping insulin receptor in the endosomes, Neuron 96 (2017) $115-129$.

[27] S. Hoyer, Glucose metabolism and insulin receptor signal transduction in Alzheimer disease, Eur. J. Pharmacol. 490 (2004) 115-125. 
[28] R. Kandimalla, V. Thirumala, P.H. Reddy, Is Alzheimer's disease a type 3 diabetes? A critical appraisal, Biochim. Biophys. Actam. 1863 (2017) 1078-1089.

[29] X. Ma, F. Fang, M. Song, S. Ma, The effect of isoliquiritigenin on learning and memory impairments induced by high-fat diet via inhibiting TNF- $\alpha$ /JNK/IRS signaling, Biochem. Biophys. Res. Commun. 464 (2015) 1090-1095.

[30] D. Petrov, I. Pedrós, G. Artiach, F.X. Sureda, E. Barroso, M. Pallàs, A. Camins, High-fat diet-induced deregulation of hippocampal insulin signalling and mitochondrial homeostasis deficiencies contribute to Alzheimer disease pathology in rodents, Biochim. Biophys. Acta. 1852 (2015) 1687-1699.

[31] L. Ho, W. Qin, P.N. Pompl, Z. Xiang, J. Wang, Z. Zhao, Y. Peng, G. Cambareri, A. Rocher, C.V. Mobbs, P.R. Hof, G.M. Pasinetti, Diet-induced insulin resistance promotes amyloidosis in a transgenic mouse model of Alzheimer's disease, FASEB J. 18 (2004) 902-904.

[32] F. Formiga, M. Pérez-Maraver, Type 3 diabetes mellitus. The revival of inhaled insulin? Endocrinol. Nutr. 61 (2014) 173-175.

[33] J.T. Coyle, D.L. Price, M.R. DeLong, Alzheimer's disease: a disorder of cortical cholinergic innervation, Science 219 (1983) 1184-1190.

[34] J. Coyle, P. Kershaw, Galantamine, a cholinesterase inhibitor that allosterically modulates nicotinic receptors: effects on the course of Alzheimer's disease, Biol. Psychiatry 49 (2001) 289-299.

[35] A. Contestabile, The history of the cholinergic hypothesis, Behav. Brain Res. 221 (2011) 334-340.

[36] E.K. Perry, B.E. Tomlinson, G. Blessed, K. Bergmann, P.H. Gibson, R.H. Perry, Correlation of cholinergic abnormalities with senile plaques and mental test scores in senile dementia, BMJ 2 (1978) 1457-1459.

[37] P.J. Whitehouse, D.L. Price, A.W. Clark, J.T. Coyle, M.R. De Long, Alzheimer disease: evidence for selective loss of cholinergic neurons in the nucleus basalis, Ann. Neurol. 10 (1981) 122-126.

[38] M. Sabbagh, J. Cummings, Progressive cholinergic decline in Alzheimer's disease: consideration for treatment with donepezil $23 \mathrm{mg}$ in patients with moderate to severe symptomatology, BMC Neurol. 11 (2011) 21.

[39] J. Hardy, D.J. Selkoe, The amyloid hypothesis of Alzheimer's disease: progress and problems on the road to therapeutics, Science 297 (2002) 353-356.

[40] D.J. Selkoe, J. Hardy, The amyloid hypothesis of Alzheimer's disease at 25 years, EMBO Mol. Med. 8 (2016) 595-608.

[41] J.A. Hardy, G.A. Higgins, Alzheimer's disease: the amyloid cascade hypothesis, Science 256 (1992) 184-185.

[42] J. Hardy, The amyloid hypothesis for Alzheimer's disease: a critical reappraisal, J. Neurochem. 110 (2009) 1129-1134.

[43] D.J. Selkoe, Alzheimer's disease is a synaptic failure, Science 298 (2002) 789-791.

[44] J.H. Toyn, M.K. Ahlijanian, Interpreting Alzheimer's disease clinical trials in light of the effects on amyloid- $\beta$, Alzheimers Res. Ther. 6 (2014) 14.

[45] J. Sevigny, P. Chiao, T. Bussière, P.H. Weinreb, L. Williams, M. Maier, R. Dunstan, S. Salloway, T. Chen, Y. Ling, J. O'Gorman, F. Qian, M. Arastu, M. Li, S. Chollate, M.S. Brennan, O. Quintero-Monzon, R.H. Scannevin, H.M. Arnold, T. Engber, K. Rhodes, J. Ferrero, Y. Hang, A. Mikulskis, J. Grimm, C. Hock, R.M. Nitsch, A. Sandrock, The antibody aducanumab reduces A $\beta$ plaques in Alzheimer's disease, Nature 537 (2016) 50-56.

[46] M. Shinohara, N. Sato, Bidirectional interactions between diabetes and Alzheimer's disease, Neurochem. Int. 108 (2017) 296-302.

[47] M.F. Egan, J. Kost, P.N. Tariot, P.S. Aisen, J.L. Cummings, B. Vellas, C. Sur, Y. Mukai, T. Voss, C. Furtek, E. Mahoney, L. Harper Mozley, R. Vandenberghe, Y. Mo, D. Michelson, Randomized trial of verubecestat for mild-to-moderate Alzheimer's disease, N. Engl. J. Med. 378 (2018) 1691-1703.

[48] J. Cummings, G. Lee, A. Ritter, K. Zhong, Alzheimer's disease drug development pipeline; 2018, Alzheimers Dement (N Y) 4 (2018) 195-214.

[49] M.D. Weingarten, A.H. Lockwood, S.Y. Hwo, M.W. Kirschner, A protein factor essential for microtubule assembly, Proc. Natl. Acad. Sci. U S A. 72 (1975) 1858-1862.

[50] M. Jin, N. Shepardson, T. Yang, G. Chen, D. Walsh, D.J. Selkoe, Soluble amyloid beta-protein dimers isolated from Alzheimer cortex directly induce tau hyperphosphorylation and neuritic degeneration, Proc. Natl. Acad. Sci. U S A. 108 (2011) 5819-5824.

[51] K. Iqbal, C.X. Gong, F. Liu, Microtubule-associated protein tau as a therapeutic target in Alzheimer's disease, Expert Opinion Ther. Targets 18 (2014) 307-318.

[52] E.H. Corder, M.A. Woodbury, I. Volkmann, D.K. Madsen, N. Bogdanovic, B. Winblad, Density profiles of Alzheimer disease regional brain pathology for the huddinge brain bank: pattern recognition emulates and expands upon braak staging, Exp. Gerontol. 35 (2000) 851-864.

[53] T. Gómez-Isla, R. Hollister, H. West, S. Mui, J.H. Growdon, R.C. Petersen, J.E. Parisi, B.T. Hyman, Neuronal loss correlates with but exceeds neurofibrillary tangles in Alzheimer's disease, Ann. Neurol. 41 (41) (1997) 17-24.

[54] A. Delacourte, A. Defossez, Alzheimer's disease: tau proteins, the promoting factors of microtubule assembly, are major components of paired helical filaments, J. Neurol. Sci. 76 (1986) 173-186.

[55] E.D. Robertson, K. Scearce-Levie, J.J. Palop, F. Yan, I.H. Cheng, T. Wu, H. Gerstein, G.Q. Yu, L. Mucke, Reducing endogenous tau ameliorates amyloid beta-induced deficits in an Alzheimer's disease mouse model, Science 316 (2007) $750-754$.

[56] M.T. Heneka, M.J. Carson, J. El Khoury, G.E. Landreth, F. Brosseron, D.L. Feinstein, A.H. Jacobs, T. Wyss-Coray, J. Vitorica, R.M. Ransohoff, K. Herrup, S.A. Frautschy, B. Finsen, G.C. Brown, A. Verkhratsky, K. Yamanaka, J. Koistinaho, E. Latz, A. Halle, G.C. Petzold, T. Town, D. Morgan, M.L. Shinohara, V.H. Perry, C. Holmes, N.G. Bazan, D.J. Brooks, S. Hunot, B. Joseph, N. Deigendesch, O. Garaschuk, E. Boddeke, C.A. Dinarello, J.C. Breitner, G.M. Cole, D.T. Golenbock, M.P. Kummer, Neuroinflammation in Alzheimer's disease, Lancet
Neurol. 14 (2015) 388-405.

[57] Benedict C. De Felice, A key role of insulin receptors in memory, Diabetes. 64 (2015) 3653-3655.

[58] F.G. De Felice, M.V. Lourenco, S.T. Ferreira, How does brain insulin resistance develop in Alzheimer's disease? Alzheimers Dement. 10 (2014) S26-32.

[59] Alzheimer's Association Report 2018, Alzheimer's disease facts and figures, Alzheimer's Dement. 14 (2018) 367-429.

[60] H. Akiyama, S. Barger, S. Barnum, B. Bradt, J. Bauer, G.M. Cole, N.R. Cooper, P. Eikelenboom, M. Emmerling, B.L. Fiebich, C.E. Finch, S. Frautschy, W.S. Griffin, H. Hampel, M. Hull, G. Landreth, L. Lue, R. Mrak, I.R. Mackenzie, P.L. McGeer, M.K. O’Banion, J. Pachter, G. Pasinetti, C. Plata-Salaman, J. Rogers, R. Rydel, Y. Shen, W. Streit, R. Strohmeyer, I. Tooyoma, F.L. Van Muiswinkel, R. Veerhuis, D. Walker, S. Webster, B. Wegrzyniak, G. Wenk, T. Wyss-Coray, Inflammation and Alzheimer's disease, Neurobiol. Aging 21 (2000) 383-421.

[61] S.W. Pimplikar, Neuroinflammation in Alzheimer's disease: from pathogenesis to a therapeutic target, J. Clin. Immunol. 34 (Suppl. 1) (2014) S64-S69.

[62] M.T. Heneka, M.P. Kummer, E. Latz, Innate immune activation in neurodegenerative disease, Nat. Rev. Immunol. 14 (2014) 463-477.

[63] M.T. Heneka, M. Sastre, L. Dumitrescu-Ozimek, A. Hanke, I. Dewachter, C. Kuiperi, K. O'Banion, T. Klockgether, F. Van Leuven, G.E. Landreth, Acute treatment with the PPARgamma agonist pioglitazone and ibuprofen reduces glial inflammation and Abeta1-42 levels in APPV717I transgenic mice, Brain 125 (2005) 1442-1453.

[64] P.L. McGeer, J.P. Guo, M. Lee, K. Kennedy, E.G. McGeer, Alzheimer's disease can Be spared by nonsteroidal anti-inflammatory drugs, J. Alzheimers Dis. 62 (2018) 1219-1222.

[65] H. Chen, J. Pellegrini, S. Aggarwal, S. Lei, S. Warach, F. Jensen, S. Lipton, Openchannel block of N-methyl-D-aspartate (NMDA) responses by memantine: therapeutic advantage against NMDA receptor-mediated neurotoxicity, J. Neurosci. 12 (1992) 4427-4436.

[66] R.H. Porter, J.T. Greenamyre, Regional variations in the pharmacology of NMDA receptor channel blockers: implications for therapeutic potential, J. Neurochem. 64 (1995) 614-623.

[67] W. Danysz, C.G. Parsons, Alzheimer's disease, $\beta$-amyloid, glutamate, NMDA receptors and memantine-searching for the connections, British J. Pharmacol. 167 (2012) 324-352.

[68] C.G. Parsons, A. Stöffler, W. Danysz, Memantine: a NMDA receptor antagonist that improves memory by restoration of homeostasis in the glutamatergic system - too little activation is bad, too much is even worse, Neuropharmacology 53 (2007) 699-723.

[69] J.W. Olney, D.F. Wozniak, N.B. Farber, Excitotoxic neurodegeneration in Alzheimer disease. New hypothesis and new therapeutic strategies, Archives Neurol. 54 (1997) 1234-1240.

[70] E.M. Snyder, Y. Nong, C.G. Almeida, S. Paul, T. Moran, E.Y. Choi, A.C. Nairn, M.W. Salter, P.J. Lombroso, G.K. Gouras, P. Greengard, Regulation of NMDA receptor trafficking by amyloid-beta, Nat. Neurosci. 8 (2005) 1051-1058.

[71] A. Ott, R.P. Stolk, A. Hofman, F. van Harskamp, D.E. Grobbee, N.M. Breteler, Association of diabetes mellitus and dementia: the Rotterdam study, Diabetologia 39 (1996) 1392-1397.

[72] A. Ott, R.P. Stolk, Fvan Harskamp, H.A. Pols, A. Hofman, M.M. Breteler, Diabetes mellitus and the risk of dementia: the Rotterdam study, Neurology 53 (1999) 1937-1942.

[73] E.M. Schrijvers, J.C. Witteman, E.J. Sijbrands, A. Hofman, P.J. Koudstaal, M.M. Breteler, Insulin metabolism and the risk of Alzheimer disease: the Rotterdam study, Neurology 75 (2010) 1982-1987.

[74] W.A. Banks, S.A. Farr, T.S. Salameh, M.L. Niehoff, E.M. Rhea, J.E. Morley, A.J. Hanson, K.M. Hansen, S. Craft, Triglycerides cross the blood-brain barrier and induce central leptin and insulin receptor resistance, Int. J. Obes. 42 (2018) 391-397.

[75] T.L. Emmerzaal, A.J. Kiliaan, D.R. Gustafson, 2003-2013: a decade of body mass index, Alzheimer's disease, and dementia, J. Alzheimers Dis. 43 (2015) 739-755.

[76] A. Rosengren, D. Skoog Gustafson, L. Wilhelmsen, Body mass index, other cardiovascular risk factors, and hospitalization for dementia, Arch. Intern. Med. 165 (2005) 321-326.

[77] E.C. Gorospe, J.K. Dave, The risk of dementia with increased body mass index, Age Ageing 36 (2007) 23-29.

[78] A. Singh-Manoux, A. Dugravot, M. Shipley, E.J. Brunner, A. Elbaz, S. Sabia, M. Kivimaki, Obesity trajectories and risk of dementia: 28 years of follow-up in the whitehall II study, Alzheimers Dement. 14 (2018) 178-186.

[79] M. Kivipelto, T. Ngandu, L. Fratiglioni, M. Viitanen, I. Kareholt, B. Winblad, E.L. Helkala, J. Tuomilehto, H. Soininen, A. Nissinen, Obesity and vascular risk factors at midlife and the risk of dementia and Alzheimer disease, Arch. Neurol. 62 (2005) 1556-1560.

[80] E. Duron, O. Hanon, Vascular risk factors, cognitve decline, and dementia, Vasc Health Risk Manag. 4 (2008) 363-381.

[81] J.T. O'Brien, H.S. Marku, Vascular risk factors and Alzheimer's disease, BMC Med. $12(2014) 218$.

[82] S.T. Ferreira, J.R. Clarke, T.R. Bomfim, F.G. De Felice, Inflammation, defective insulin signaling, and neuronal dysfunction in Alzheimer's disease, Alzheimers Dement. 10 (2014) S76-S83.

[83] M.P. Lambert, A.K. Barlow, B.A. Chromy, C. Edwards, R. Freed, M. Liosatos, T.E. Morgan, I. Rozovsky, B. Trommer, K.L. Viola, P. Wals, C. Zhang, C.E. Finch, G.A. Krafft, W.L. Klein, Diffusible, nonfibrillar ligands derived from Abeta1-42 are potent central nervous system neurotoxins, Proc. Natl. Acad. Sci. U S A. 95 (1998) 6448-6453.

[84] S.T. Ferreira, W.L. Klein, The a $\beta$ oligomer hypothesis for synapse failure and 
memory loss in Alzheimer's disease, Neurobiol. Learn Mem. 96 (2011) 529-543.

[85] S.T. Ferreira, M.N. Vieira, F.G. De Felice, Soluble protein oligomers as emerging toxins in Alzheimer's and other amyloid diseases, IUBMB Life 59 (2007) 332-345.

[86] K.L. Viola, W.L. Klein, Amyloid $\beta$-oligomers in Alzheimer's disease pathogenesis, treatment, and diagnosis, Acta Neuropathol. 129 (2015) 183-206.

[87] M.V. Lourenco, J.R. Clarke, R.L. Frozza, T.R. Bomfim, L. Forny-Germano, A.F. Batista, L.B. Sathler, J. Brito-Moreira, O.B. Amaral, C.A. Silva, L. FreitasCorrea, S. Espírito-Santo, P. Campello-Costa, J.C. Houzel, W.L. Klein, C. Holscher, J.B. Carvalheira, A.M. Silva, L.A. Velloso, D.P. Munoz, S.T. Ferreira, F.G. De Felice, TNF- $\alpha$ mediates PKR-dependent memory impairment and brain IRS-1 inhibition induced by Alzheimer's $\beta$-amyloid oligomers in mice and monkeys, Cell Metab. 18 (2013) 831-843.

[88] M.V. Lourenco, S.T. Ferreira, F.G. De Felice, Neuronal stress signaling and eIF2 $\alpha$ phosphorylation as molecular links between Alzheimer's disease and diabetes, Prog. Neurobiol. 129 (2015) 37-57.

[89] E.N. Cline, M.A. Bicca, K.L. Viola, W.L. Klein, The amyloid- $\beta$ oligomer hypothesis: beginning of the third decade, J. Alzheimers Dis. 64 (2018) S567-S610.

[90] D. Nuzzo, P. Picone, S. Baldassano, L. Caruana, E. Messina, A. Marino Gammazza, F. Cappello, F. Mulè, M. Di Carlo, Insulin resistance as Common molecular denominator linking obesity to Alzheimer's disease, Curr. Alzheimer Res. 12 (2015) $723-735$.

[91] O. Busquets, M. Ettcheto, M. Pallàs, C. Beas-Zarate, E. Verdaguer, C. Auladell, J. Folch, A. Camins, Long-term exposition to a high fat diet favors the appearance of $\beta$-amyloid depositions in the brain of C57BL/6J mice. A potential model of sporadic Alzheimer's disease, Mech. Ageing Dev. 162 (2017) 38-45.

[92] S.E. Arnold, I. Lucki, B.R. Brookshire, G.C. Carlson, C.A. Browne, H. Kazi, S. Bang, B.R. Choi, Y. Chen, M.F. McMullen, S.F. Kim, High fat diet produces brain insulin resistance, synaptodendritic abnormalities and altered behavior in mice, Neurobiol. Dis. 67 (2014) 79-87.

[93] S. Hao, A. Dey, X. Yu, A.M. Stranahan, Dietary obesity reversibly induces synaptic stripping by microglia and impairs hippocampal plasticity, Brain Behav. Immun. 51 (2016) 230-239.

[94] D.M. Osborne, D.P. Fitzgerald, K.E. O'Leary, B.M. Anderson, C.C. Lee, P.M. Tessier, E.C. McNay, Intrahippocampal administration of a domain antibody that binds aggregated amyloid- $\beta$ reverses cognitive deficits produced by diet-induced obesity, Biochim. Biophys. Acta 1860 (2016) 1291-1298.

[95] E.M. Knight, I.V. Martins, S. Gümüsgöz, S.M. Allan, C.B. Lawrence, High-fat dietinduced memory impairment in triple-transgenic Alzheimer's disease (3xTgAD) mice is independent of changes in amyloid and tau pathology, Neurobiol. Aging 35 (2014) 1821-1832.

[96] M. Vandal, P.J. White, G. Chevrier, C. Tremblay, I. St-Amour, E. Planel, A. Marette, F. Calon, Age-dependent impairment of glucose tolerance in the 3xTgAD mouse model of Alzheimer's disease, FASEB J. 29 (2015) 4273-4284.

[97] J. Wang, B.J. Gu, C.L. Masters, Y.J. Wang, A systemic view of Alzheimer disease insights from amyloid- $\beta$ metabolism beyond the brain, Nat. Rev. Neurol. 13 (2017) 612-623.

[98] Y. Zhang, B. Zhou, B. Deng, F. Zhang, J. Wu, Y. Wang, Y. Le, Q. Zhai, Amyloid- $\beta$ induces hepatic insulin resistance in vivo via JAK2, Diabetes 62 (2013) 1159-1166.

[99] Y. Zhang, B. Zhou, F. Zhang, J. Wu, Y. Hu, Y. Liu, Q. Zhai, Amyloid- $\beta$ induces hepatic insulin resistance by activating JAK2/STAT3/SOCS-1 signaling pathway, Diabetes 61 (2012) 1434-1443.

[100] L. Zhao, B. Teter, T. Morihara, G.P. Lim, S.S. Ambegaokar, O.J. Ubeda, S.A. Frautschy G.M., Cole GM. Insulin-degrading enzyme as a downstream target of insulin receptor signaling cascade: implications for Alzheimer's disease intervention, J. Neurosci. 24 (2004) 11120-11126.

[101] Z. Liu, I.Y. Patil, T. Jiang, H. Sancheti, J.P. Walsh, B.L. Stiles, F. Yin, E. Cadenas, High-fat diet induces hepatic insulin resistance and impairment of synaptic plasticity, PLoS One 10 (2015) 10 e0128274.

[102] H.H. Ruiz, T. Chi, A.C. Shin, C. Lindtner, W. Hsieh, M. Ehrlich, S. Gandy, C. Buettner, Increased susceptibility to metabolic dysregulation in a mouse model of Alzheimer's disease is associated with impaired hypothalamic insulin signaling and elevated BCAA levels, Alzheimers Dement. 12 (2016) 851-861.

[103] L. Katsouri, K. Blondrath, M. Sastre, Peroxisome proliferator-activated receptor- $\gamma$ cofactors in neurodegeneration, IUBMB Life 64 (2012) 958-964.

[104] L. Katsouri, Y.M. Lim, K. Blondrath, I. Eleftheriadou, L. Lombardero, A.M. Birch, N. Mirzaei, E.E. Irvine, N.D. Mazarakis, M. Sastre, PPAR $\gamma$-coactivator-1 $\alpha$ gene transfer reduces neuronal loss and amyloid- $\beta$ generation by reducing $\beta$-secretase in an Alzheimer's disease model, Proc. Natl. Acad. Sci. U S A. 113 (2016) 12292-12297.

[105] L. Katsouri, C. Parr, N. Bogdanovic, M. Willem, M. Sastre, PPAR $\gamma$ co-activator-1 $\alpha$ (PGC- $1 \alpha$ ) reduces amyloid- $\beta$ generation through a PPAR $\gamma$-dependent mechanism, J. Alzheimers Dis. 25 (2011) 151-162.

[106] W. Qin, V. Haroutunian, P. Katsel, C.P. Cardozo, L. Ho, J.D. Buxbaum, G.M. Pasinetti, PGC-1alpha expression decreases in the Alzheimer disease brain as a function of dementia, Archives Neurol. 66 (66) (2009) 352-361.

[107] I.V. Martins, J. Rivers-Auty, S.M. Allan, C.B. Lawrence, Mitochondrial abnormalities and synaptic loss underlie memory deficits seen in mouse models of obesity and Alzheimer's disease, J. Alzheimers Dis. 55 (2017) 915-932.

[108] S.K. Sah, C. Lee, J.H. Jang, G.H. Park, Effect of high-fat diet on cognitive impairment in triple-transgenic mice model of Alzheimer's disease, Biochem. Biophys. Res. Commun. 493 (2017) 731-736.

[109] B. Lin, Y. Hasegawa, K. Takane, N. Koibuchi, C. Cao, S. Kim-Mitsuyama, High-fatdiet intake enhances cerebral amyloid angiopathy and cognitive impairment in a mouse model of Alzheimer's disease, independently of metabolic disorders, J. Am. Heart Assoc. 5 (2016) 5 pii: e003154.
[110] P. Thériault, A. ElAli, S. Rivest, High fat diet exacerbates Alzheimer's diseaserelated pathology in APPswe/PS1 mice, Oncotarget 7 (2016) 67808-67827.

[111] V. Kothari, Y. Luo, T. Tornabene, A.M. O’Neill, M.W. Greene, T. Geetha, J.R. Babu, High fat diet induces brain insulin resistance and cognitive impairment in mice, Biochim. Biophys. Acta 1863 (2017) 499-508.

[112] M. Kohjima, Y. Sun, L. Chan, Increased food intake leads to obesity and insulin resistance in the tg2576 Alzheimer's disease mouse model, Endocrinology 151 (2010) 1532-1540.

[113] L.E. Lyn-Cook, M.Jr. Lawton, M. Tong, E. Silbermann, L. Longato, P. Jiao, P. Mark, J.R. Wands, H. Xu, S.M. de la Monte, Hepatic ceramide May mediate brain insulin resistance and neurodegeneration in type 2 diabetes and Non-alcoholic steatohepatitis, J. Alzheimers Dis. 16 (2009) 715-729.

[114] I. Arrieta-Cruz, R. Gutiérrez-Juárez, The role of insulin resistance and glucose metabolism dysregulation in the development of Alzheimer's disease, Rev. Investig. Clin. 68 (2016) 53-58.

[115] I. Arrieta-Cruz, C.M. Knight, R. Gutiérrez-Juárez, Acute exposure of the mediobasal hypothalamus to amyloid- $325-35$ perturbs hepatic glucose metabolism, J. Alzheimers Dis. 46 (2015) 843-848.

[116] J.R. Clarke, E. Lyra, N.M. Silva, C.P. Figueiredo, R.L. Frozza, J.H. Ledo, D. Beckman, C.K. Katashima, D. Razolli, B.M. Carvalho, R. Frazão, M.A. Silveira, F.C. Ribeiro, T.R. Bomfim, F.S. Neves, W.L. Klein, R. Medeiros, F.M. LaFerla, J.B. Carvalheira, M.J. Saad, D.P. Munoz, L.A. Velloso, S.T. Ferreira, F.G. De Felice, Alzheimer-associated $a \beta$ oligomers impact the central nervous system to induce peripheral metabolic deregulation, EMBO Mol. Med. 7 (2015) 190-210.

[117] A.E. Roher, C.L. Esh, T.A. Kokjohn, E.M. Castaño, G.D. Van Vickle, W.M. Kalback, R.L. Patton, D.C. Luehrs, I.D. Daugs, Y.M. Kuo, M.R. Emmerling, H. Soares, J.F. Quinn, J. Kaye, D.J. Connor, N.B. Silverberg, C.H. Adler, J.D. Seward, T.G. Beach, M.N. Sabbagh, Amyloid beta peptides in human plasma and tissues and their significance for Alzheimer's disease, Alzheimers Dement. 5 (2009) $18-29$.

[118] J. Miklossy, H. Qing, A. Radenovic, A. Kis, B. Vileno, F. Làszló, L. Miller, R.N. Martins, G. Waeber, V. Mooser, F. Bosman, K. Khalili, N. Darbinian, P.L. McGeer, Beta amyloid and hyperphosphorylated tau deposits in the pancreas in type 2 diabetes, Neurobiol. Aging 31 (2010) 1503-1515.

[119] M. Shinohara, N. Sato, Bidirectional interactions between diabetes and Alzheimer's disease, Neurochem Int. 108 (2017) 296-302.

[120] C. Duran-Aniotz, V.H. Cornejo, S. Espinoza, Á.O. Ardiles, D.B. Medinas, C. Salazar, A. Foley, I. Gajardo, P. Thielen, T. Iwawaki, W. Scheper, C. Soto, A.G. Palacios, J.J.M. Hoozemans, C. Hetz, IRE1 signaling exacerbates Alzheimer's disease pathogenesis, Acta Neuropathol. 134 (2017) 489-506.

[121] C. Duran-Aniotz, G. Martínez, C. Hetz, Memory loss in Alzheimer' s disease: are the alterations in the UPR network involved in the cognitive impairment? Front. Aging Neurosci. 6 (2014) 8.

[122] V.H. Cornejo, C. Hetz, The unfolded protein response in Alzheimer's disease, Semin Immunopathol. 35 (2013) 277-292.

[123] R.C. Chang, K.C. Suen, C.H. Ma, W. Elyaman, H.K. Ng, J. Hugon, Involvement of double-stranded RNA-dependent protein kinase and phosphorylation of eukaryotic initiation factor-2alpha in neuronal degeneration, J. Neurochem. 83 (2002) 1215-1225.

[124] Y. Gerakis, C. Hetz, Emerging roles of ER stress in the etiology and pathogenesis of Alzheimer's disease, FEBS J. 285 (2018) 995-1011.

[125] C. Hetz, S. Saxena, ER stress and the unfolded protein response in neurodegeneration, Nat. Rev. Neurol. 13 (2017) 477-491.

[126] T. O'Connor, K.R. Sadleir, E. Maus, R.A. Velliquette, J. Zhao, S.L. Cole, W.A. Eimer, B. Hitt, L. Bembinster, S. Lammich, S.F. Lichtenthaler, S.S. Hébert, B. De Strooper, C. Haass, D.A. Bennett, R. Vassar, Phosphorylation of the translation initiation factor eIF2a increases BACE1 levels and promotes amyloidogenesis, Neuron 60 (2008) 988-1009.

[127] V. Valenzuela, G. Martínez, C. Duran-Aniotz, C. Hetz, Gene therapy to target ER stress in brain diseases, Brain Res. 1648 (2016) 561-570.

[128] J. Lu, D.M. Wu, Y.L. Zheng, B. Hu, W. Cheng, Z.F. Zhang, Q. Shan, Ursolic acid improves high fat diet-induced cognitive impairments by blocking endoplasmic reticulum stress and IкB kinase $\beta$ /nuclear factor-кB-mediated inflammatory pathways in mice, Brain Behav. Immun. 25 (201) (2011) 1658-1667.

[129] J. Hugon, F. Mouton-Liger, J. Dumurgier, C. Paquet, PKR involvement in Alzheimer's disease, Alzheimers Res. Ther. 9 (2017) 83.

[130] K.D. Hwang, M.S. Bak, S.J. Kim, S. Rhee, Y.S. Lee, Restoring synaptic plasticity and memory in mouse models of Alzheimer's disease by PKR inhibition, Mol. Brain 10 (2017) 57.

[131] L. Devi, M. Ohno, Phospho-eIF2a level is important for determining abilities of BACE1 reduction to rescue cholinergic neurodegeneration and memory defects in 5XFAD mice, PLoS One 5 (2010) e12974.

[132] L. Devi, M. Ohno, Mechanisms that lessen benefits of $\beta$-secretase reduction in a mouse model of Alzheimer's disease, Transl. Psychiatry 3 (2013) e284.

[133] L. Devi, M. Ohno, PERK mediates eIF2 $\alpha$ phosphorylation responsible for BACE1 elevation, CREB dysfunction and neurodegeneration in a mouse model of Alzheimer's disease, Neurobiol. Aging 35 (2014) 2272-2281.

[134] W. Yang, X. Zhou, H.R. Zimmermann, D.R. Cavener, E. Klann, T. Ma, Repression of the eIF2 $\alpha$ kinase PERK alleviates mGluR-LTD impairments in a mouse model of Alzheimer's disease, Neurobiol. Aging 41 (2016) 19-24.

[135] F. Mouton-Liger, C. Paquet, J. Dumurgier, C. Bouras, L. Pradier, F. Gray, J. Hugon, Oxidative stress increases BACE1 protein levels through activation of the PKReIF2 $\alpha$ pathway, Biochim. Biophys. Acta 1822 (2012) 885-896.

[136] T. Ma, M.A. Trinh, A.J. Wexler, C. Bourbon, E. Gatti, P. Pierre, D.R. Cavener, E. Klann, Suppression of eIF2a kinases alleviates Alzheimer's disease-related plasticity and memory deficits, Nat. Neurosci. 16 (2013) 1299-1305. 
[137] C. Sims-Robinson, A. Bakeman, R. Glasser, J. Boggs, C. Pacut, E.L. Feldman, The role of endoplasmic reticulum stress in hippocampal insulin resistance, Exp. Neurol. 277 (2016) 261-267.

[138] O. Busquets, M. Ettcheto, E. Verdaguer, R.D. Castro-Torres, C. Auladell, C. BeasZarate, J. Folch, A. Camins, JNK1 inhibition by Licochalcone A leads to neuronal protection against excitotoxic insults derived of kainic acid, Neuropharmacology 131 (2018) 440-452.

[139] L. Liang, J. Chen, L. Zhan, X. Lu, X. Sun, H. Sui, L. Zheng, H. Xiang, F. Zhang, Endoplasmic reticulum stress impairs insulin receptor signaling in the brains of obese rats, PLoS One 10 (5) (2015) e0126384.

[140] K. Ohta, A. Mizuno, S. Li, M. Itoh, M. Ueda, E. Ohta, Y. Hida, M.X. Wang, M. Furoi, Y. Tsuzuki, M. Sobajima, Y. Bohmoto, T. Fukushima, M. Kobori, T. Inuzuka, T. Nakagawa, Endoplasmic reticulum stress enhances $\gamma$-secretase activity, Biochem. Biophys. Res. Commun. 416 (2011) 362-366.

[141] M. Hayakawa, M. Itoh, K. Ohta, S. Li, M. Ueda, M.X. Wang, E. Nishida, S. Islam, C.S. Suzuki, K. Ohzawa, M. Kobori, T. Inuzuka, T. Nakagawa, Quercetin reduces eIF2 $\alpha$ phosphorylation by GADD34 induction, Neurobiol. Aging 36 (2015) 2509-2518.

[142] H. Gao, P. Yan, S. Zhang, S. Nie, F. Huang, H. Han, Q. Deng, Q. Huang, W. Yang, H. Wu, P. Yao, K. Ye, J. Xu, L. Liu, Chronic alpha-linolenic acid treatment alleviates age-associated neuropathology: roles of PERK/eIF2 $\alpha$ signaling pathway, Brain Behav Immun. 57 (2016) 314-325.

[143] T. Wyss-Coray, Inflammation in Alzheimer disease: driving force, bystander or beneficial response? Nat. Med. 12 (2006) 1005-1015.

[144] O. Guillemot-Legris, G.G. Muccioli, Obesity-induced neuroinflammation: beyond the hypothalamus, Trends Neurosci. 40 (2017) 237-253.

[145] U.K. Hanisch, H. Kettenmann, Microglia: active sensor and versatile effector cells in the normal and pathologic brain, Nat. Neurosci. 10 (2007) 1387-1394.

[146] W.J. Streit, Q.S. Xue, J. Tischer, I. Bechmann, Microglial pathology, Acta Neuropathol. Commun. 26 (2014) 2142.

[147] M.L. Block, L. Calderón-Garcidueñas, Air pollution: mechanisms of neuroinflammation and CNS disease, Trends Neurosci. 32 (2009) 506-516.

[148] M. Schwartz, O. Butovsky, W. Brück, U.K. Hanisch, Microglial phenotype: is the commitment reversible? Trends Neurosci. 29 (2006) 68-74.

[149] F. Zhang, L. Jiang, Neuroinflammation in Alzheimer's disease, Neuropsychiatr. Dis. Treat. 11 (2015) 243-245.

[150] W. Swardfager, K. Lanctôt, L. Rothenburg, A. Wong, J. Cappell, N. Herrmann, A meta-analysis of cytokines in Alzheimer's disease, Biol. Psychiatry 68 (2010) 930-941.

[151] A. Carreras-Sureda, P. Pihán, C. Hetz, Calcium signaling at the endoplasmic reticulum: fine-tuning stress responses, Cell Calcium 70 (2018) 24-31.

[152] G. Castro, M.F. Areias, L. Weissmann, P.G. Quaresma, C.K. Katashima, M.J. Saad, P.O. Prada, Diet-induced obesity induces endoplasmic reticulum stress and insulin resistance in the amygdala of rats, FEBS Open Bio. 11 (2013) 443-449.

[153] G.S. Hotamisligil, Endoplasmic reticulum stress and the inflammatory basis of metabolic disease, Cell 140 (2010) 900-917.

[154] J. Benzler, G.K. Ganjam, K. Legler, S. Stöhr, M. Krüger, J. Steger, A. Tups, Acute inhibition of central c-Jun N-terminal kinase restores hypothalamic insulin signalling and alleviates glucose intolerance in diabetic mice, J. Neuroendocrinol. 25 (2013) 446-454.

[155] U. Ozcan, Q. Cao, E. Yilmaz, A.H. Lee, N.N. Iwakoshi, E. Ozdelen, G. Tuncman, C. Görgün, L.H. Glimcher, G.S. Hotamisligil, Endoplasmic reticulum stress links obesity, insulin action, and type 2 diabetes, Science 306 (2004) 457-461.

[156] M. Cissé, E. Duplan, F. Checler, The transcription factor XBP1 in memory and cognition: implications in Alzheimer disease, Mol. Med. 4 (2017) 22.

[157] D. Popov, Endoplasmic reticulum stress and the onsite function of resident PTP1B, Biochem. Biophys. Res. Commun. 422 (2012) 535-538.

[158] G.J. Song, M. Jung, J.H. Kim, H. Park, M.H. Rahman, S. Zhang, Z.Y. Zhang, D.H. Park, I.K. Lee, K. Suk, A novel role for protein tyrosine phosphatase 1B as a positive regulator of neuroinflammation, J. Neuroinflammation 13 (2016) 86.

[159] Y.M. Jeon, S. Lee, S. Kim, Y. Kwon, K. Kim, C.G. Chung, S. Lee, S.B. Lee, H.J. Kim, Neuroprotective effects of protein tyrosine phosphatase 1B inhibition against ER stress- induced toxicity, Mol. Cells 40 (2017) 1e11.

[160] Y.F. Mao, Z. Guo, T. Zheng, Y. Jiang, Y. Yan, X. Yin, Y. Chen, B. Zhang, Intranasal insulin alleviates cognitive deficits and amyloid pathology in young adult APPswe/PS1dE9 mice, Aging Cell 15 (2016) 893-902.

[161] S. Craft, L.D. Baker, T.J. Montine, S. Minoshima, G.S. Watson, A. Claxton, M. Arbuckle, M. Callaghan, E. Tsai, S.R. Plymate, P.S. Green, J. Leverenz, D. Cross, B. Gerton, Intranasal insulin therapy for Alzheimer disease and amnestic mild cognitive impairment: a pilot clinical trial, Arch. Neurol. 69 (2012) 29-38.

[162] S. Craft, A. Claxton, L.D. Baker, A.J. Hanson, B. Cholerton, E.H. Trittschuh, D. Dahl, E. Caulder, B. Neth, T.J. Montine, Y. Jung, J. Maldjian, C. Whitlow, S. Friedman, Effects of regular and long-acting insulin on cognition and Alzheimer's disease biomarkers: a pilot clinical trial, J. Alzheimers Dis. 57 (2017) $1325-1334$.

[163] V. Ott, C. Benedict, B. Schultes, J. Born, M. Hallschmid, Intranasal administration of insulin to the brain impacts cognitive function and peripheral metabolism, Diabetes Obes. Metab. 14 (2012) 214-221.

[164] P.L. McClean, Jalewa J, C. Hölscher, Prophylactic liraglutide treatment prevents amyloid plaque deposition, chronic inflammation and memory impairment in APP/PS1 mice, Behav. Brain Res. 293 (2015) 96-106.

[165] M. Bomba, D. Ciavardelli, E. Silvestri, L.-M. Canzoniero, R. Lattanzio, P. Chiappini, M. Piantelli, C. Di Ilio, A. Consoli, S.L. Sensi, Exenatide promotes cognitive enhancement and positive brain metabolic changes in PS1-KI mice but has no effects in 3xTg-AD animals, Cell Death Dis. 2 (2013) 4 e612.

[166] A.M. Duffy, C. Hölscher, The incretin analogue D-Ala2GIP reduces plaque load, astrogliosis and oxidative stress in an APP/PS1 mouse model of Alzheimer's disease, Neuroscience 228 (2013) 294-300.

[167] T. Li, J.J. Jiao, C. Hölscher, M.N. Wu, J. Zhang, J.Q. Tong, X.F. Dong, X.S. Qu, Y. Cao, H.Y. Cai, Q. Su, J.S. Qi, A novel GLP-1/GIP/Gcg triagonist reduces cognitive deficits and pathology in the 3xTg mouse model of Alzheimer's disease, Hippocampus 28 (2018) 358-372.

[168] C. Rotermund, G. Machetanz, J.C. Fitzgerald, The therapeutic potential of metformin in neurodegenerative diseases, Front. Endocrinol. 19 (2018) 9400.

[169] Z. Ou, X. Kong, X. Sun, X. He, L. Zhang, Z. Gong, J. Huang, B. Xu, D. Long, J. Li, Q. Li, L. Xu, A. Xuan, Metformin treatment prevents amyloid plaque deposition and memory impairment in APP/PS1 mice, Brain Behav. Immun. 69 (2018) $351-363$.

[170] E. Barini, O. Antico, Y. Zhao, F. Asta, V. Tucci, T. Catelani, R. Marotta, H. Xu, L. Gasparini, Metformin promotes tau aggregation and exacerbates abnormal behavior in a mouse model of tauopathy, Mol. Neurodegener. 11 (2016) 16.

[171] C. Infante-Garcia, J.J. Ramos-Rodriguez, C. Hierro-Bujalance, E. Ortegon, E. Pickett, R. Jackson, F. Hernandez-Pacho, T. Spires-Jones, M. Garcia-Alloza, Antidiabetic polypill improves Central pathology and cognitive impairment in a mixed model of Alzheimer's disease and type 2 diabetes, Mol. Neurobiol. 55 (2018) 6130-6144.

[172] A.M. Koenig, D. Mechanic-Hamilton, S.X. Xie, M.F. Combs, A.R. Cappola, L. Xie, J.A. Detre, D.A. Wolk, S.E. Arnold, Effects of the insulin sensitizer metformin in Alzheimer disease: pilot data from a randomized placebo-controlled crossover study, Alzheimer Dis. Assoc. Disord. 31 (2017) 107-113.

[173] S. Xu, G. Liu, X. Bao, J. Wu, S. Li, B. Zheng, R. Anwyl, Q. Wang, Rosiglitazone prevents amyloid- $\beta$ oligomer-induced impairment of synapse formation and plasticity via increasing dendrite and spine mitochondrial number, J. Alzheimers Dis. (2014) 239-251.

[174] M. Gold, C. Alderton, M. Zvartau-Hind, S. Egginton, Saunders A.M, M. Irizarry, S. Craft, G. Landreth, U. Linnamägi, S. Sawchak, Rosiglitazone monotherapy in mild-to-moderate Alzheimer's disease: results from a randomized, double-blind, placebo-controlled phase III study, Dement. Geriatr. Cogn. Disord. 30 (2010) $131-146$.

[175] C. Harrington, S. Sawchak, C. Chiang, J. Davies, C. Donovan, A.M. Saunders, M. Irizarry, B. Jeter, M. Zvartau-Hind, C.H. van Dyck, M. Gold, Rosiglitazone does not improve cognition or global function when used as adjunctive therapy to AChE inhibitors in mild-to-moderate Alzheimer's disease: two phase 3 studies, Curr. Alzheimer Res. 8 (2011) 592-606.

[176] M.T. Heneka, A. Fink, G. Doblhamme, Effect of pioglitazone medication on the incidence of dementia, Ann. Neurol. 78 (2015) 284-294.

[177] C.M. Fernandez-Martos, R.A.K. Atkinson, M.I. Chuah, A.E. King, J.C. Vickers, Combination treatment with leptin and pioglitazone in a mouse model of Alzheimer's disease, Alzheimers Dement. 3 (2016) 92-106.

[178] D.S. Geldmacher, T. Fritsch, M.J. McClendon, G. Landreth, A randomized pilot clinical trial of the safety of pioglitazone in treatment of patients with Alzheimer disease, Arch. Neurol. 68 (68) (2011) 45-50.

[179] B.W. Miller, K.C. Willett, A.R. Desilets, Rosiglitazone and pioglitazone for the treatment of Alzheimer's disease, Ann. Pharmacother. 45 (2011) 1416-1424.

[180] T. Sato, K. Hanyu, H. Kanetaka, H. Sakurai, T. Iwamoto, Efficacy of PPAR-gamma agonist pioglitazone in mild Alzheimer disease, Neurobiol. Aging 32 (2011) $1626-1633$.

[181] J. Toba, M. Nikkuni, M. Ishizeki, A. Yoshii, N. Watamura, T. Inoue, T. Ohshima, PPAR $\gamma$ agonist pioglitazone improves cerebellar dysfunction at pre-a $\beta$ deposition stage in APPswe/PS1dE9 Alzheimer's disease model mice, Biochem. Biophys. Res. Commun. 473 (2016) 1039-1044.

[182] Z. Nowakowska, A review of anti-infective and anti-inflammatory chalcones, Eur. J. Med. Chem. 42 (2007) 125-137.

[183] M.J. Matos, S. Vazquez-Rodriguez, E. Uriarte, L. Santana, Potential pharmacological uses of chalcones: a patent review (from June 2011-2014), Expert Opin. Ther. Pat. 25 (2015) 351-366.

[184] H.N. Lee, H.J. Cho, D.Y. Lim, Y.H. Kang, K.W. Lee, J.H. Park, Mechanisms by which licochalcone e exhibits potent anti-inflammatory properties: studies with phorbol ester-treated mouse skin and lipopolysaccharide-stimulated murine macrophagesv, Int. J. Mol. Sci. 14 (2013) 10926-10943.

[185] L. Wang, R. Yang, B. Yuan, Y. Liu, C. Liu, The antiviral and antimicrobial activities of licorice, a widely used Chinese herb, Acta Pharm. Sin. B 5 (2015) 310-315.

[186] S.S. Kim, J. Lim, Y. Bang, J. Gal, S.U. Lee, Y.C. Cho, G. Yoon, B.Y. Kang, S.H. Cheon, H.J. Choi, Licochalcone E activates Nrf2/antioxidant response element signaling pathway in both neuronal and microglial cells: therapeutic relevance to neurodegenerative disease, J. Nutr. Biochem. 23 (2012) 1314-1323.

[187] X. Chu, L. Jiang, M. Wei, X. Yang, M. Guan, X. Xie, J. Wei, D. Liu, D. Wang, Attenuation of allergic airway inflammation in A murine model of asthma by licochalcone A, Immunopharmacol. Immunotoxicol. 35 (2013) 653-661.

[188] M.M. Rafi, R.T. Rosen, A. Vassil, C.T. Ho, H. Zhang, G. Ghai, G. Lambert, R.S. Di Paola, Modulation of bcl-2 and cytotoxicity by licochalcone-A, a novel estrogenic flavonoid, Anticancer Res. 20 (2000) 2653-2658.

[189] K.H. Jeon, E. Lee, K.Y. Jun, J.E. Eom, S.Y. Kwak, Y. Na, Y. Kwon, Neuroprotective effect of synthetic chalcone derivatives as competitive dual inhibitors against $\mu$ calpain and cathepsin B through the downregulation of tau phosphorylation and insoluble a $\beta$ peptide formation, Eur. J. Med. Chem. 121 (2016) 433-444.

[190] Z. Cao, J. Yang, R. Xu, Q. Song, X. Zhang, H. Liu, X. Qiang, Y. Li, Z. Tan, Y. Deng, Design, synthesis and evaluation of 4'-OH-flurbiprofen-chalcone hybrids as potential multifunctional agents for Alzheimer's disease treatment, Bioorg. Med. Chem. 26 (2018) 1102-1115.

[191] S. Gao, S. Howard, P.V. LoGrasso, Pharmacological inhibition of c-jun N-terminal kinase reduces food intake and sensitizes leptin's anorectic signaling actions, Sci. 
Rep. 7 (2017) 41795.

[192] S.L. Macauley, M. Stanley, E.E. Caesar, S.A. Yamada, M.E. Raichle, R. Perez, T.E. Mahan, C.L. Sutphen, D.M. Holtzman, Hyperglycemia modulates extracellular amyloid- $\beta$ concentrations and neuronal activity in vivo, J. Clin. Invest. 125 (2015) 2463-2467.

[193] G.J. Biessels, L.P. Reagan, Hippocampal insulin resistance and cognitive dysfunction, Nat. Rev. Neurosci. 16 (2015) 660-671.

[194] C.L. Masters, R. Bateman, K. Blennow, C.C. Rowe, R.A. Sperling, J.L. Cummings, Alzheimer's disease, Nat. Rev. Dis. Primers. 1 (2015) 15056.

[195] M.M. Mielke, V.V. Bandaru, N.J. Haughey, J. Xia, L.P. Fried, S. Yasar, M. Albert, V. Varma, G. Harris, E.B. Schneider, P.V. Rabins, K. Bandeen-Roche, C.G. Lyketsos, M.C. Carlson, Serum ceramides increase the risk of Alzheimer disease: the women's health and aging study II, Neurology 79 (2012) 633-641.

[196] T.A. Dar, I.A. Sheikh, S.A. Ganie, R. Ali, L.R. Singh, S.H. Gan, M.A. Kamal, M.A. Zargar, Molecular linkages between diabetes and Alzheimer's disease: current scenario and future prospects, CNS Neurol. Disord. Drug Targets 13 (2014) 290-298.

[197] C.D. Chapman, H.B. Schiöth, C.A. Grillo, C. Benedict, Intranasal insulin in Alzheimer's disease: food for thought, Neuropharmacology 136 (2018) 196-201.

[198] A. Claxton, L.D. Baker, A. Hanson, E.H. Trittschuh, B. Cholerton, A. Morgan, M. Callaghan, Arbuckle M, C. Behl, S. Craft, Long-acting intranasal insulin detemir improves cognition for adults with mild cognitive impairment or early-stage Alzheimer's disease dementia, J. Alzheimers Dis. 44 (2015) 897-906.

[199] Q. Jiang, M. Heneka, G.E. Landreth, The role of peroxisome proliferator-activated receptor-gamma (PPARgamma) in Alzheimer's disease: therapeutic implications, CNS Drugs 22 (2008) 1-14.

[200] T. Ma, X. Du, J.E. Pick, G. Sui, M. Brownlee, E. Klann, Glucagon-like peptide-1 cleavage product GLP-1(9-36) amide rescues synaptic plasticity and memory deficits in Alzheimer's disease model mice, J. Neurosci. 32 (2012) 13701-13708.

[201] I. Moreno-Gonzalez, G. Edwards, N. Salvadores, M. Shahnawaz, R. Diaz-Espinoza, C. Soto, Molecular interaction between type 2 diabetes and Alzheimer's disease through cross-seeding of protein misfolding, Mol. Psychiatry 22 (2017) 1327-1334.

[202] S. Merlo, S. Spampinato, P.L. Canonico, A. Copani, M.A. Sortino, Alzheimer's disease: brain expression of a metabolic disorder? Trends Endocrinol. Metab. 21 (2010) 537-544.

[203] A. Salminen, A. Kauppinen, T. Suuronen, K. Kaarniranta, J. Ojala, ER stress in alzheimer's disease: a novel neuronal trigger for inflammation and alzheimer's pathology, J Neuroinflammation 6 (2009) 41.

[204] Q.L. Ma, F. Yang, E.R. Rosario, O.J. Ubeda, W. Beech, D.J. Gant, P.P. Chen, B. Hudspeth, C. Chen, Y. Zhao, H.V. Vinters, S.A. Frautschy, G.M. Cole, Betaamyloid oligomers induce phosphorylation of tau and inactivation of insulin receptor substrate via c-jun $\mathrm{N}$-terminal kinase signaling: suppression by omega-3 fatty acids and curcumin, J. Neurosci. 29 (2009) 9078-9089.

[205] J. Furusawa, M. Funakoshi-Tago, T. Mashino, K. Tago, H. Inoue, Y. Sonoda, T. Kasahara, Glycyrrhiza inflata-derived chalcones, licochalcone A, licochalcone B and licochalcone D, inhibit phosphorylation of NF-kappaB p65 in LPS signaling pathway, Int. Immunopharmacol. 9 (2009) 499-507.

[206] K. Yao, H. Chen, M.H. Lee, H. Li, W. Ma, C. Peng, N.R. Song, K.W. Lee, A.M. Bode, Z. Dong, Z. Dong, A. Licochalcone, A natural inhibitor of c-jun N-terminal kinase 1 , Cancer Prev. Res. (Phila) 7 (2014) 139-149.

[207] E.J. Yang, G.H. Park, K.S. Song, Neuroprotective effects of liquiritigenin isolated from licorice roots on glutamate-induced apoptosis in hippocampal neuronal cells, Neurotoxicology 39 (2013) 114-123.

[208] C. Zou, Y. Shi, J. Ohli, U. Schüller, M.M. Dorostkar, J. Herms, Neuroinflammation impairs adaptive structural plasticity of dendritic spines in a preclinical model of Alzheimer's disease, Acta Neuropathol. 131 (2016) 235-246.

[209] L.S. Honig, B. Vellas, M. Woodward, M. Boada, R. Bullock, M. Borrie, K. Hager, V. Andreasen, E. Scarpini, H. Liu-Seifert, M. Case, R.A. Dean, A. Hake, K. Sundell, V. Poole Hoffmann, C. Carlson, R. Khanna, M. Mintun, R. DeMattos, K.J. Selzler, E. Siemers, Trial of solanezumab for mild dementia due to Alzheimer's disease, N. Engl. J. Med. 378 (2018) 321-330.

[210] M. Yarchoan, J.B. Toledo, E.B. Lee, Z. Arvanitakis, H. Kazi, L.Y. Han, N. Louneva, V.M. Lee, S.F. Kim, J.Q. Trojanowski, S.E. Arnold, Abnormal serine phosphorylation of insulin receptor substrate 1 is associated with tau pathology in Alzheimer's disease and tauopathies, Acta Neuropathol. 128 (2014) 679-689.

[211] A. Claxton, L.D. Baker, C.W. Wilkinson, E.H. Trittschuh, D. Chapman, G.S. Watson, B. Cholerton, S.R. Plymate, M. Arbuckle, S. Craft, Sex and ApoE genotype differences in treatment response to two doses of intranasal insulin in adults with mild cognitive impairment or Alzheimer's disease, J. Alzheimers Dis. 35 (2013) 789-797.

[212] M.A. Reger, G.S. Watson, W.H. Frey 2nd, L.D. Baker, B. Cholerton, M.L. Keeling, D.A. Belongia, M.A. Fishel, S.R. Plymate, G.D. Schellenberg, M.M. Cherrier, S. Craft, Effects of intranasal insulin on cognition in memory-impaired older adults: modulation by APOE genotype, Neurobiol. Aging (2006) 451-458.

[213] M.A. Reger, G.S. Watson, P.S. Green, L.D. Baker, B. Cholerton, M.A. Fishe, S.R. Plymate, N.M. Cherrier, G.D. Schellenberg, W.H. Frey 2nd, S. Craft, Intranasal insulin administration dose-dependently modulates verbal memory and plasma amyloid-beta in memoryimpaired older adults, J. Alzheimer Dis. 13 (2008) 323-331.

[214] M.A. Reger, G.S. Watson, P.S. Green, C.W. Wilkinson, L.D. Baker, B. Cholerton, M.A. Fishel, S.R. Plymate, J.C. Breitner, W. DeGroodt, P. Mehta, S. Craft, Intranasal insulin improves cognition and modulates beta-amyloid in early $\mathrm{AD}$, Neurology 70 (2008) 440-448. 